\title{
Use of topical bromfenac for treating ocular pain and inflammation beyond cataract surgery: a review of published studies
}

This article was published in the following Dove Press journal:

Clinical Ophthalmology

\section{Barry A Schechter}

Cornea and Cataract Service, Florida Eye Microsurgical Institute, Boynton Beach, FL, USA
Correspondence: Barry A Schechter Cornea and Cataract Service, Florida Eye Microsurgical Institute, 1717 Woolbright Rd, Boynton Beach, FL 33426, USA

Email baschechter@me.com

\begin{abstract}
Topical ophthalmic nonsteroidal anti-inflammatory drugs (NSAIDs) are commonly used to treat postoperative inflammation and pain following cataract surgery and for treatment and prophylaxis of pseudophakic cystoid macular edema (CME). Bromfenac is a brominated NSAID with strong in vitro anti-inflammatory potency. Like other ophthalmic NSAIDs, bromfenac is often used outside of the cataract surgery setting. This paper provides an overview of bromfenac's preclinical ocular pharmacology and pharmacokinetics, followed by a review of 23 published clinical studies in which various marketed bromfenac formulations were used for conditions other than cataract surgery or pseudophakic CME. These include: post-refractive eye surgery; macular edema associated with diabetes, uveitis, or retinal vein occlusion; inflammation associated with age-related macular degeneration; pain related to intravitreal injections; and other ocular anterior segment and surface disorders with an inflammatory component. The published evidence reviewed supports the safety and effectiveness of bromfenac in these additional ophthalmic indications. Bromfenac was well tolerated when given alone or in combination with intravitreal anti-vascular endothelial growth factor agents, topical corticosteroids, or topical mast-cell stabilizers. The most common adverse event reported was ocular irritation. No serious adverse events (ie, corneal epithelial disorders) were reported, although the majority of studies did not systematically evaluate potential side effects. Corneal complications, such as melts reported with diclofenac and ketorolac, were not observed with bromfenac in the studies. In summary, published study data support the clinical utility of bromfenac in various ocular disorders beyond post-cataract surgery. Additional studies are warranted to further define the potential role of bromfenac ophthalmic solution in clinical practice.
\end{abstract}

Keywords: bromfenac, clinical studies, ocular inflammation, pain, safety

\section{Introduction}

Nonsteroidal anti-inflammatory drugs (NSAIDs) are increasingly being utilized in ophthalmology for a variety of indications. NSAIDs exert anti-inflammatory and analgesic activity primarily through nonselective inhibition of cyclooxygenase-1 (COX-1) and cyclooxygenase-2 (COX-2) enzymes. ${ }^{1-4}$ By inhibiting the COX pathway, NSAIDs limit conversion of arachidonic acid to prostaglandins. ${ }^{1,3,5}$ Prostaglandins play a key role in stimulating pain and ${ }^{1}$ promoting miosis, vasodilation, disruption of the blood-ocular barrier, and leukocyte migration. Thus, prevention of prostaglandin formation by NSAIDs results in anti-inflammatory and other clinically beneficial effects (Figure 1). ${ }^{1}$ Reduction of vascular endothelial growth 


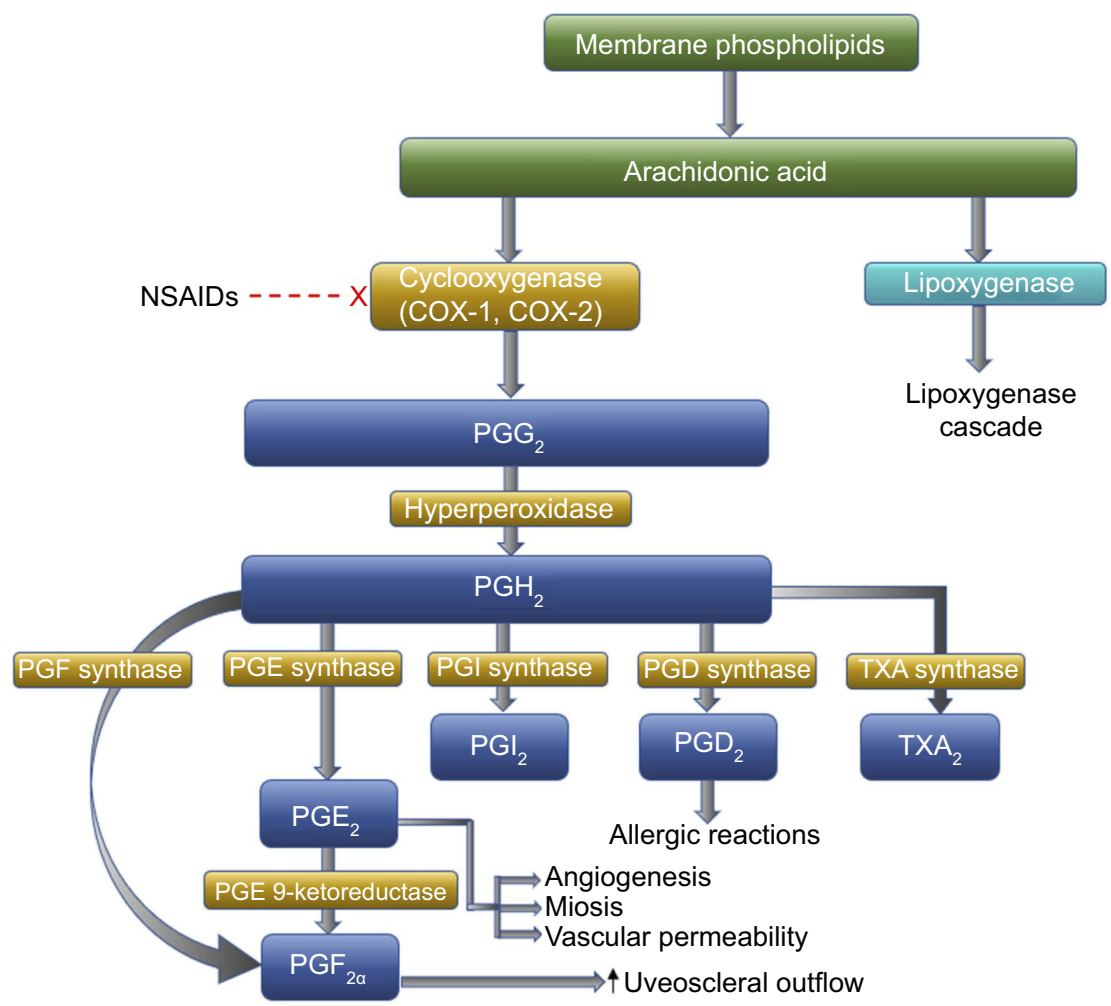

Figure I Cyclooxygenase pathway of prostaglandin production from membrane bound arachidonic acid and site of action of NSAIDs. Adapted from Adv Ther, Voolume 27/ Edition 10, Schechter BA, Trattler W, Efficacy and safety of bromfenac for the treatment of corneal ulcer pain, 756-76I, Copyright (2010), with permission from Adis, part of Springer Science+Business Media.'

factor (VEGF) activity via inhibition of COX-2 may also contribute to beneficial effects of NSAIDs for some therapeutic indications in the retina. ${ }^{1}$

Topical administration of NSAIDs is preferred for most ophthalmic indications as it results in high ocular drug concentrations, inclusive of therapeutic levels in posterior ocular tissues, with minimal systemic adverse events (AEs) when compared to systemic administration. ${ }^{6,7}$ Currently, several ophthalmic NSAIDs are indicated for the management of post-cataract surgery pain and inflammation (nepafenac, bromfenac) or post-cataract surgery inflammation (ketorolac, diclofenac). ${ }^{8-11}$ Other FDA-approved indications include the temporary relief of pain and photophobia in patients undergoing corneal refractive surgery (diclofenac) ${ }^{11}$ and the temporary relief of itching due to seasonal allergic conjunctivitis (SAC) (ketorolac). ${ }^{12}$ Beyond these approved indications, and due to their ability to inhibit COX activity, other indications have been explored, including prevention and treatment of cystoid macular edema (CME) after cataract or refractive surgery; reduction of pain, discomfort, and inflammation following refractive surgery; treatment of macular edema associated with diabetes and ocular diseases, such as uveitis, branch vein retinal occlusion, and corneal ulcer pain., ${ }^{13-25}$
Topical NSAIDs may also be beneficial in the treatment of age-related macular degeneration (AMD), which has a complex pathogenesis that includes a major inflammatory component. ${ }^{26}$ In addition, the anti-inflammatory properties of these agents may alleviate some of the signs and symptoms of anterior segment and ocular inflammatory surface disorders. ${ }^{27-33}$

Bromfenac is an NSAID developed and marketed for topical ophthalmic use. A twice-daily (BID) bromfenac $0.1 \%$ ophthalmic solution was approved in Japan in 2000 (Bronuck $^{\circledR}$; Senju Pharmaceutical Co., Ltd., Osaka, Japan) as a treatment for pain and inflammation associated with inflammatory eye disorders. The same BID formulation was subsequently FDA-approved in 2005 as bromfenac ophthalmic solution $0.09 \%$ (Xibrom $^{\circledR}$; ISTA Pharmaceuticals Inc., Irvine, CA, USA); equivalent in dose to the Japanese formulation (which is labeled as the salt) for the treatment of postoperative inflammation following cataract surgery. This same formulation is marketed as Yellox ${ }^{\circledR}$ in Europe. The US product was discontinued in 2011 following the introduction in 2010 of a once-daily (QD) formulation (bromfenac $0.09 \%$; Bromday ${ }^{\circledR}$, ISTA Pharmaceuticals Inc.) indicated for treating postoperative inflammation and pain following cataract 
extraction with posterior chamber intraocular lens (IOL) implantation. A newer QD formulation of bromfenac (Prolensa ${ }^{\circledR}$; Bausch \& Lomb Incorporated), FDA-approved in 2013 , has a lower and more physiologic $\mathrm{pH}$ ( 7.8 versus 8.3 for Xibrom), allowing for a reduced concentration $(0.07 \%)$ while maintaining bioavailability. ${ }^{10,34}$ Because bromfenac is a weak acid, reducing the $\mathrm{pH}$ decreases the proportion of ionized drug, facilitating penetration into targeted ocular tissues and allowing for the lower concentration to be utilized. ${ }^{35,36}$ Bromsite $^{\circledR}$ (bromfenac ophthalmic solution 0.075\%; Sun Pharmaceutical Industries, Cranbury, NJ, USA) was approved in 2016 for treatment of postoperative inflammation and prevention of ocular pain in patients undergoing cataract surgery and is administered BID. ${ }^{37}$ BromSite is formulated in DuraSite ${ }^{\circledR}$ (Sun Pharmaceutical Industries), a mucoadhesive matrix known to retain drug on the ocular surface. $^{38}$

Bromfenac is the only brominated ophthalmic NSAID available (Figure 2). Halogenation of the molecule through the addition of a bromine atom in the 4-position of the benzoyl ring confers bromfenac with increased potency against COX-1 and COX-2 compared to other NSAIDs. ${ }^{39-44}$ Multiple studies have evaluated the $\mathrm{IC}_{50}$ (the drug concentration required to inhibit COX enzyme activity by $50 \%$ ) of bromfenac with that of other NSAIDs using a variety of enzyme sources, including tissue extracts and/or recombinant COX enzyme preparations. The studies demonstrated that the potency of bromfenac in inhibiting both COX-1 and COX-2 was improved over that of other NSAIDs, except for ketorolac, for which the $\mathrm{IC}_{50}$ against COX-1 was lower in one study (Table 1).

Bromination also increases the lipophilicity of bromfenac, which, in turn, may facilitate ocular tissue<smiles>Nc1c(CC(=O)O)cccc1C(=O)c1ccc(Br)cc1</smiles>

Diclofenac<smiles>O=C(O)Cc1ccccc1Nc1c(Cl)cccc1Cl</smiles>

Ketorolac

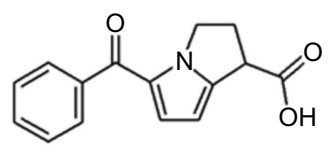

Nepafenac

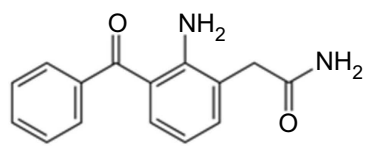

Figure 2 Chemical structures of bromfenac and other ophthalmic NSAIDs.

Table I Comparison of cyclooxygenase inhibitory activity of topical NSAIDs

\begin{tabular}{|l|l|l|l|}
\hline Study & NSAID & $\begin{array}{l}\text { COX-I IC } \\
(\mu \mathrm{M})\end{array}$ & $\begin{array}{l}\text { COX-2 IC } \\
(\mu \mathrm{M})\end{array}$ \\
\hline Kida $2014^{42}$ & Bromfenac & 0.00556 & 0.00745 \\
& Diclofenac & 0.0555 & 0.0307 \\
& Amfenac & 0.0153 & 0.0204 \\
\hline Walters $2007^{43}$ & Bromfenac & 0.0864 & 0.0112 \\
& Ketorolac & 0.0139 & 0.0911 \\
& Amfenac & 0.138 & 0.00177 \\
& Nepafenac & 82.3 & $>1000$ \\
\hline Waterbury & Bromfenac & 0.210 & 0.0066 \\
$2006^{44}$ & Ketorolac & 0.020 & 0.12 \\
& Diclofenac & 0.0079 & NA \\
\hline
\end{tabular}

Notes: Reprinted from PLoS One, Volume 9/ Edition 5, Kida T, Kozai S, Takahashi $H$, Isaka M, Tokushige H, Sakamoto T, Pharmacokinetics and efficacy of topically applied nonsteroidal anti-inflammatory drugs in retinochoroidal tissues in rabbits, e9648I, Copyright (2014), permission from Public Library of Science (PLoS) is not needed as this manuscript is an open-access article distributed under the terms of the Creative Commons Attributions License. ${ }^{42}$ Reprinted from J Cataract Refract Surg, Volume 33/ Edition 9, Walters T, Raizman M, Ernest P, Gayton J, Lehmann R, In vivo pharmacokinetics and in vitro pharmacodynamics of nepafenac, amfenac, ketorolac, and bromfenac, 1539-1545, Copyright (2007), with permission from Elsevier. ${ }^{43}$ Reprinted from Curr Med Res Opin, Volume 22/ Edition 6, Waterbury LD, Silliman D, Jolas T, Comparison of cyclooxygenase inhibitory activity and ocular anti-inflammatory effects of ketorolac tromethamine and bromfenac sodium, II33I 140, Copyright (2006), with permission from Taylor \& Francis Ltd (http://www. tandfonline.com).$^{44}$

Abbreviation: $\mathrm{IC}_{50}$, half maximal inhibitory concentration; NA, not applicable.

penetration through the cornea's layers. ${ }^{41}$ The pharmacokinetics of various bromfenac ophthalmic solutions have been studied in rabbit ocular tissues, while in humans, aqueous and vitreous humor concentrations have been evaluated at several time points post-instillation. In rabbits, a single $50-\mu \mathrm{L}$ ocular dose of bromfenac $0.09 \%$ solution resulted in detection of bromfenac in all ocular tissues (conjunctiva, cornea, lens, iris-ciliary body, aqueous humor, choroid, retina, and sclera) except for the vitreous humor, with levels sustained over $24 \mathrm{hrs}$, as determined by HPLC. ${ }^{45}$ Similarly, following a single $50-\mu \mathrm{L}$ topical dose of ${ }^{14} \mathrm{C}$-bromfenac $0.07 \%$ solution, bromfenac was detected using liquid scintillation chromatography in ocular tissues for up to $24 \mathrm{hrs}$ with a similar distribution as bromfenac $0.09 \%$ (single $50-\mu \mathrm{L}$ dose). ${ }^{34}$ In another rabbit PK study comparing the ocular penetration of bromfenac following a QD $40-\mu \mathrm{L}$ topical dose of either bromfenac $0.075 \%$ solution formulated in DuraSite or bromfenac $0.07 \%$ solution for a total of 9 days, there were no apparent differences in drug concentrations in either the anterior and posterior ocular tissues as measured by HPLC. ${ }^{46}$ As expected, bromfenac 
$0.075 \%$ in DuraSite dosed BID (the approved clinical dosing regimen) achieved significantly higher ocular concentrations compared to bromfenac $0.07 \%$ dosed QD. ${ }^{46}$ However, both formulations reached tissue levels in excess of the reported $\mathrm{IC}_{50}$ for bromfenac. Concentrations of bromfenac in ocular surface tissues (cornea, conjunctiva) were not evaluated in this study, but, based on a previous study evaluating the ocular distribution of azithromycin formulated in DuraSite, ${ }^{47}$ ocular surface concentrations are expected to be higher following instillation of bromfenac $0.075 \%$ in DuraSite as compared to bromfenac $0.07 \%$. While there were no safety signals reported in a 16-day clinical safety and efficacy study of bromfenac $0.075 \%$ in DuraSite in patients undergoing cataract surgery, ${ }^{48}$ the impact of NSAIDs on ocular surface integrity, particularly in patients with underlying corneal disease, is a potential class concern, and further studies are needed to establish ocular surface levels of the new DuraSite formulation.

In humans, topical ocular instillation of one drop of bromfenac $0.09 \%$ prior to cataract surgery resulted in peak levels of bromfenac in the aqueous humor at the time of surgery which were several-fold higher than the $\mathrm{IC}_{50}$ for COX-2, or $0.0112 \mu \mathrm{M} .{ }^{43}$ A single $50-\mu \mathrm{L}$ drop of bromfenac $0.1 \%$ instilled prior to the initiation of cataract surgery resulted in maintenance of clinically effective aqueous humor levels (above the $\mathrm{IC}_{50}$ value for COX-2) for more than $12 \mathrm{hrs}^{49}$ Reductions in aqueous prostaglandin E2 concentrations at the time of surgery have also been demonstrated with bromfenac $0.09 \%$, administered either BID 2 days preoperatively or BID 1 day preoperatively plus 1 drop in the morning before surgery, in patients undergoing cataract surgery. ${ }^{50,51}$ Bromfenac $0.075 \%$ in DuraSite and bromfenac $0.09 \%$ dosed QD for 2 days and then $3 \mathrm{hrs}$ prior to cataract surgery both achieved aqueous humor concentrations in excess of reported $\mathrm{IC}_{50}$ values (Table 1), with a higher concentration achieved with the bromfenac/DuraSite formulation. ${ }^{52}$ In one study of patients undergoing vitrectomy (not related to a vitreous hemorrhage), penetration of topical bromfenac $0.09 \%$ into the vitreous humor was observed at a concentration sufficient to significantly reduce vitreous prostaglandin E2 concentrations ${ }^{53}$ however these results were inconsistent with those of an earlier smaller study in vitrectomy patients, which did not observe a significant reduction in vitreous prostaglandin E2 concentrations following topical bromfenac $0.09 \%$ administration. ${ }^{54}$
The safety and efficacy of bromfenac for the management of pain and inflammation following cataract surgery, its approved indication, has been reviewed extensively elsewhere, ${ }^{5-57}$ as has its use for prevention and treatment of CME following cataract surgery. ${ }^{58}$ The purpose of the current paper was to provide a comprehensive review of published studies which have evaluated the use of bromfenac for the treatment of anterior or posterior ocular inflammatory conditions beyond the post-cataract surgery setting.

\section{Search strategy}

A search was conducted of the MEDLINE ${ }^{\circledR}$ database using the search terms ("bromfenac" NOT "oral") with no time constraints. This search returned 194 citations. All citations were hand-screened and included if they described a clinical study of any type (prospective, retrospective, case series, masked, open label) addressing the use of bromfenac for an ocular indication other than post-cataract surgery (ie, treatment of inflammation/pain or treatment/ prevention of $\mathrm{CME}$ ). Case reports were not included. Foreign-language papers with English abstracts were eligible for inclusion. Of the 194 citations, 173 were excluded for the following reasons: pertained to cataract surgery/CME prevention $(\mathrm{n}=56)$; animal/in vitro research $(\mathrm{n}=36)$; reviews $(\mathrm{n}=26)$; pertained to systemic bromfenac $(\mathrm{n}=25) ; \quad$ pharmacokinetic/pharmacodynamic studies $(n=11)$; case reports $(n=6)$; comments/letters $(n=5)$; studies in which bromfenac was not the focus of the research $(\mathrm{n}=5)$; and studies involving healthy volunteers $(\mathrm{n}=3)$. An additional three citations were identified through scanning bibliographies of published papers. A supplemental search of EMBASE using the terms "bromfenac NOT (cataract surgery)" did not identify any additional relevant citations. Thus, 23 citations were included in this review.

\section{Post-refractive eye surgery}

Photorefractive keratectomy (PRK), laser in situ keratomileusis (LASIK), and laser-assisted subepithelial keratectomy (LASEK) are effective surgical procedures used to correct low to moderate myopia and hyperopia. While safe, each technique can induce some degree of ocular pain, inflammation, and/or discomfort. For instance, ablation of the corneal epithelium and associated sensory nerves is a source of postoperative pain in PRK. ${ }^{59,60}$ LASIK uses a microkeratome to raise a corneal flap, which is replaced following laser ablation, but disruption of nerve fibers below the surface in the corneal stroma can 
cause significant discomfort. LASEK is a modification of LASIK in which the flap is more superficial and does not include anterior stromal tissue, thus maintaining the cornea's biomechanical stability and lowering the risk of flaprelated complications, yet patients undergoing this technique can still experience pain or discomfort. Although LASEK would theoretically be expected to cause less postoperative pain than PRK, a meta-analysis of 11 randomized, controlled trials did not find consistent differences between these procedures in pain scores at 1, 2, or 3 days postsurgery. ${ }^{59}$ Topical NSAIDs have been used to reduce postoperative pain and inflammation following refractive eye surgeries. $^{16-22}$

Several studies have evaluated bromfenac for the treatment of ocular discomfort following refractive surgery. In a prospective, double-masked, placebo-controlled case series, 64 patients (120 eyes) were treated with one of four regimens of bromfenac $0.07 \%$ and/or artificial tears (AT) to reduce perioperative ocular discomfort related to LASIK surgery (one drop immediately before and after the LASIK procedure): presurgical and postsurgical bromfenac; presurgical bromfenac and postsurgical AT; presurgical AT and postsurgical bromfenac; or presurgical and postsurgical AT (control). ${ }^{61}$ Mean postoperative eye pain rating and an averaged all-symptoms rating performed by patients (eye pain, tearing, itching, foreign body sensation, photophobia, discharge, haziness) using the Ocular Comfort Grading Assessment (OCGA) were both lower $1 \mathrm{hr}$ postsurgery in subjects treated with presurgical bromfenac/ postsurgical AT $(P=0.02)$. Among patients who received bromfenac both pre- and postsurgically, an all-symptoms OCGA mean score of zero, indicating no eye pain or other symptoms of discomfort, was reported at the 2-hr postsurgical assessment ( $P<0.05$ vs control). Ocular discharge and tearing were the symptoms most improved by the bromfenac-containing regimens. Significant reductions in tearing vs control (AT only) were observed with presurgical bromfenac/postsurgical AT ( 1 and $3 \mathrm{hrs}$ ), pre- and postsurgical bromfenac (2 and 5 hrs), and presurgical AT/postsurgical bromfenac (5 hrs). Significant reductions in discharge vs control were observed at all time points through $5 \mathrm{hrs}$ with pre- and postsurgical bromfenac and presurgical bromfenac/postsurgical AT; presurgical AT/postsurgical bromfenac was significantly different from control only at the 2-hr evaluation. Visual acuity (VA) was similar between all treatments at day 1 and 3 months postoperatively. No clinically significant AEs were observed.

An open-label study in 60 patients (120 eyes) who had undergone LASEK surgery followed by a 7-day course of topical dexamethasone $0.1 \%$ four times daily (QID) compared bromfenac $0.1 \%$ BID to a tapered regimen of fluorometholone $0.1 \%$ (three times daily [TID] for 3 weeks, then BID for 4 weeks, then QD for 4 weeks) administered over the subsequent 11 weeks. ${ }^{62}$ The bromfenac group demonstrated improved VA compared to the fluorometholone group at 1 month $(P<0.05)$ and similar VA at other time points. At 6 months, all bromfenactreated eyes achieved preoperative best corrected VA, while three eyes in the fluorometholone group failed to achieve preoperative best corrected VA. There were no significant differences between groups in intraocular pressure (IOP) or corneal topography at any time point. Haze was noted in two bromfenac-treated eyes at 1 month and at 2 months, and two fluorometholone-treated eyes at 1 month, but resolved with more frequent NSAID instillation and did not affect VA. Overall, bromfenac was reported to be well tolerated, and no patients discontinued treatment.

Four studies compared bromfenac to ketorolac following refractive eye surgery. ${ }^{63-66}$ A prospective, randomized study compared bromfenac $0.1 \%$ BID (32 patients/eyes) with $0.5 \%$ ketorolac QID (32 patients/eyes), each given for 3 days before and 1 day after LASEK surgery. ${ }^{63}$ Although the duration of postoperative irritative symptoms (a single outcome assessing symptoms such as pain, photophobia, foreign body sensation, and tearing) was significantly shorter in the bromfenac group (median, 2.0 vs 14.0 days; $P=0.004$ ), there were no significant differences between groups in corneal healing time or VA as measured from day 1 through month 3 . A majority $(87.5 \%$; 28/32) of patients receiving ketorolac reported eye irritation and burning after administration (eg, pain and burning sensation), while no discomfort was reported in the bromfenac group.

In a prospective, double-masked study, 29 patients (58 eyes) undergoing PRK were randomized to treatment with nepafenac $0.1 \%(\mathrm{n}=15$ patients $/ 30$ eyes $)$, bromfenac $0.09 \%$ $(n=6$ patients $/ 12$ eyes), or ketorolac $0.4 \%(n=8$ patients $/ 16$ eyes); each topical NSAID was administered TID beginning 1 day preoperatively and continuing for 1 week postoperatively. ${ }^{64}$ By day 3, all groups showed a significant reduction in pain score compared to before NSAID use $(P<0.05)$. Time to reepithelialization (complete closure) occurred significantly sooner with nepafenac (mean $\pm \mathrm{SD}, 5.5 \pm 1.59$ days) and ketorolac (5.6 \pm 1.23 days) compared to bromfenac $(7.3 \pm 2.53$ days; $P<0.05)$. Time to healing in this study was longer than reported in a previous study comparing nepafenac and ketorolac. ${ }^{82}$ The authors 


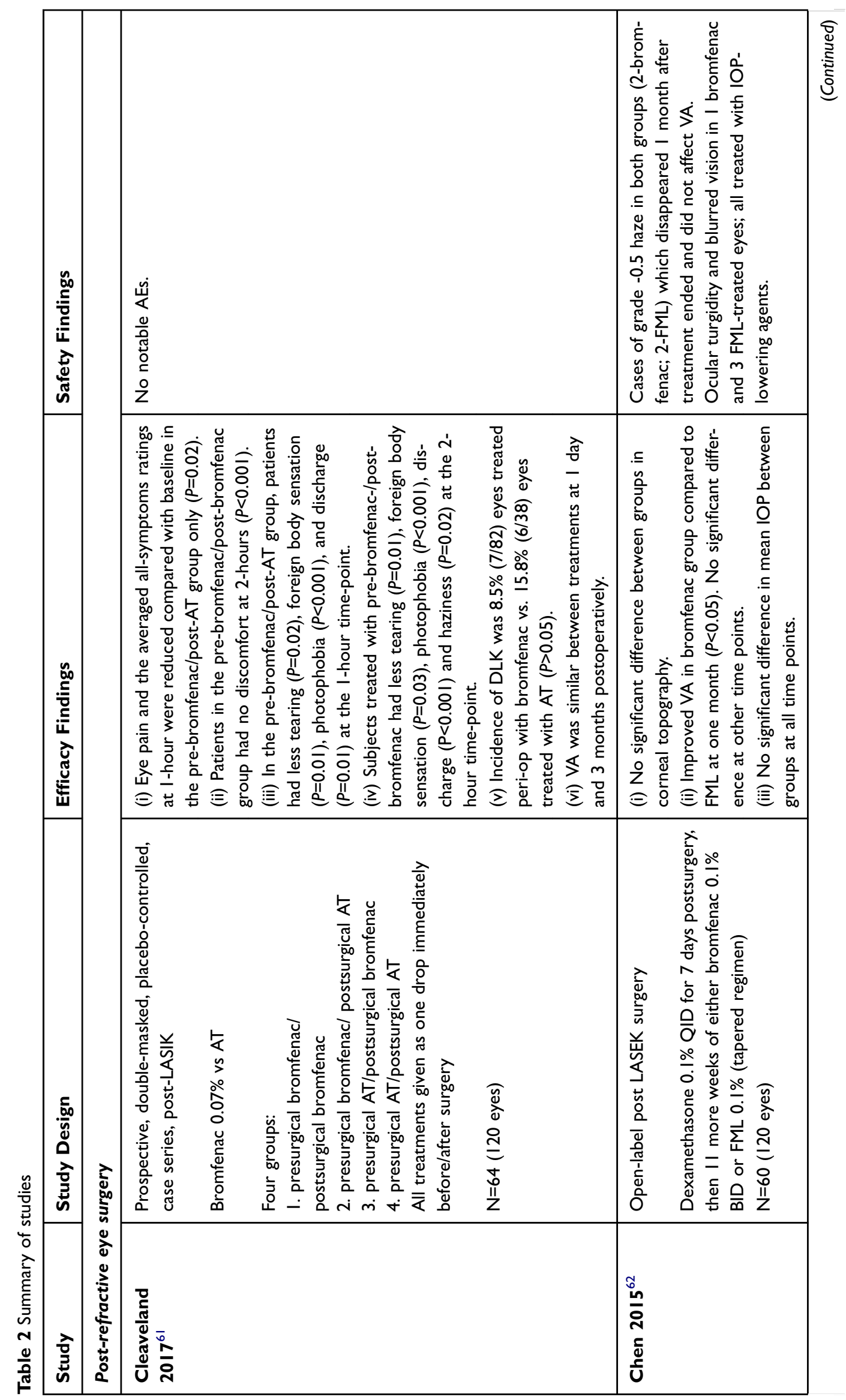




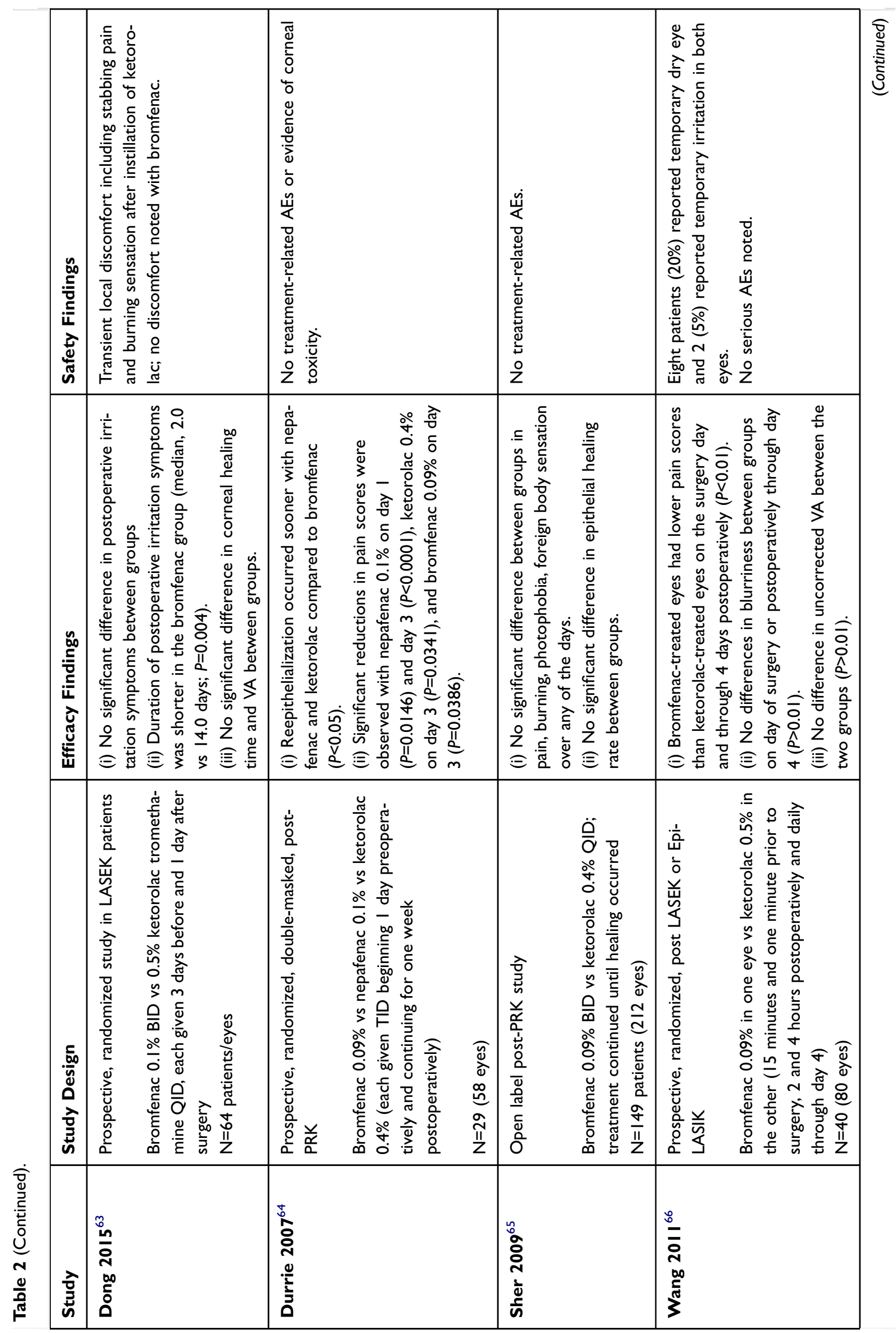




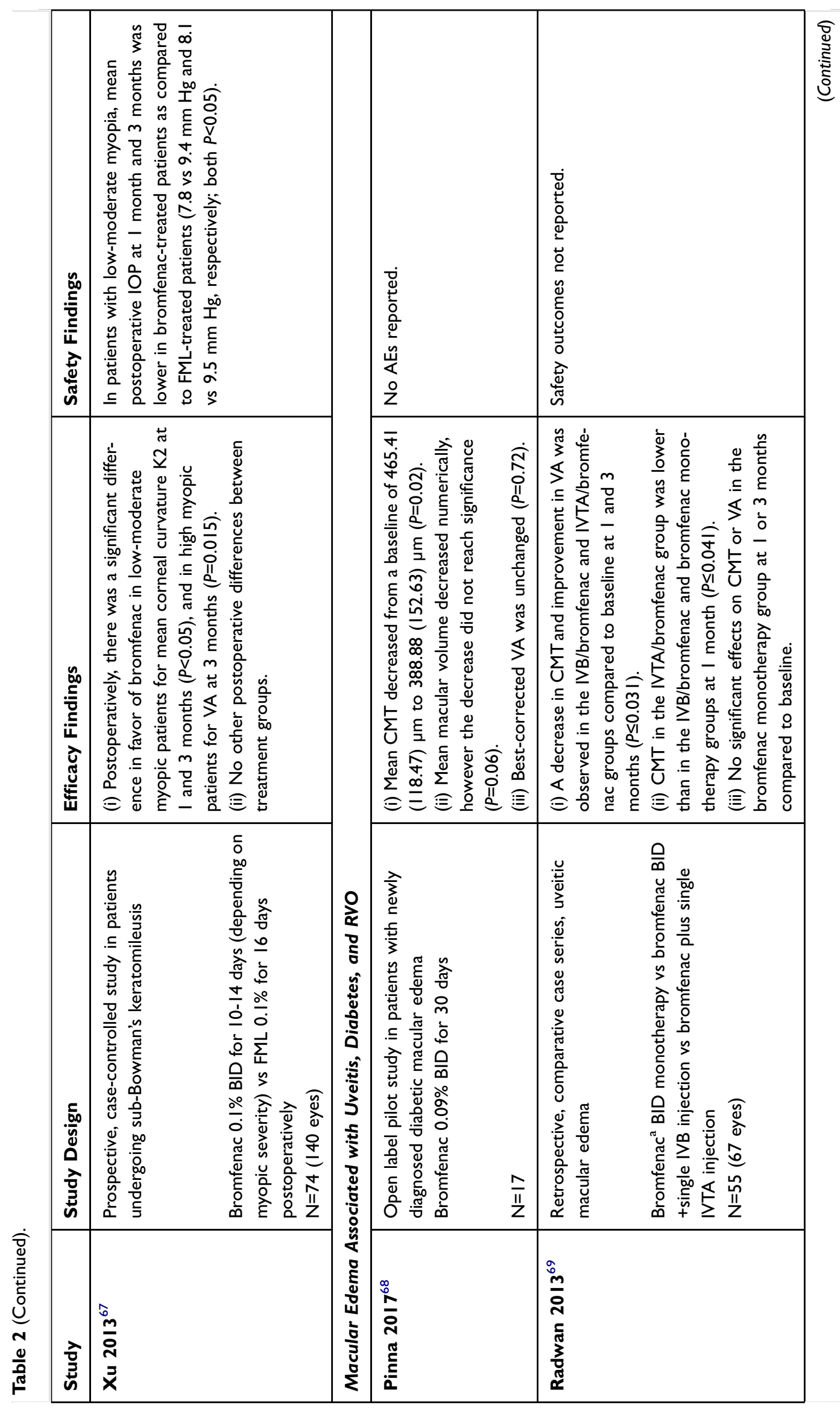




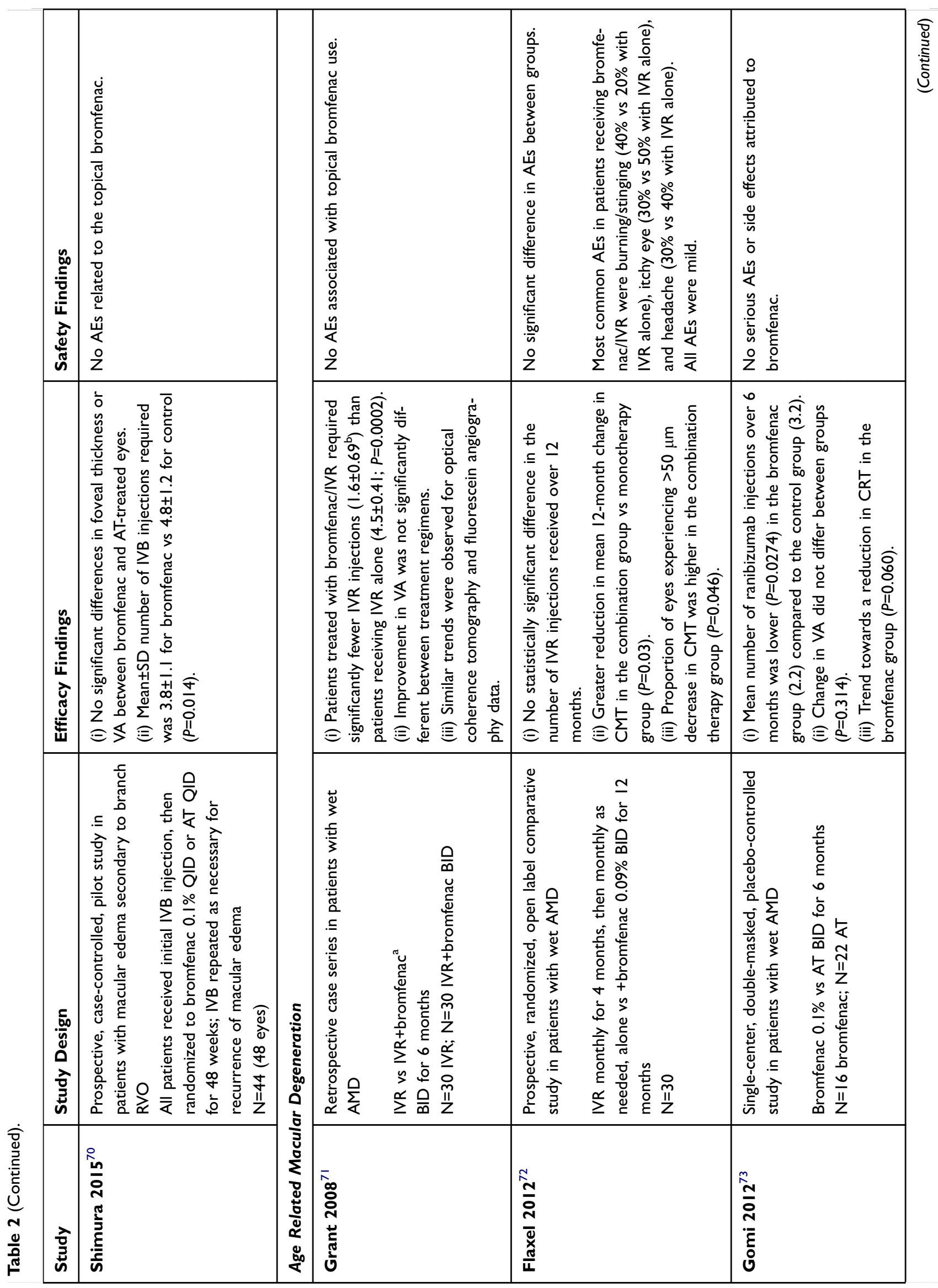




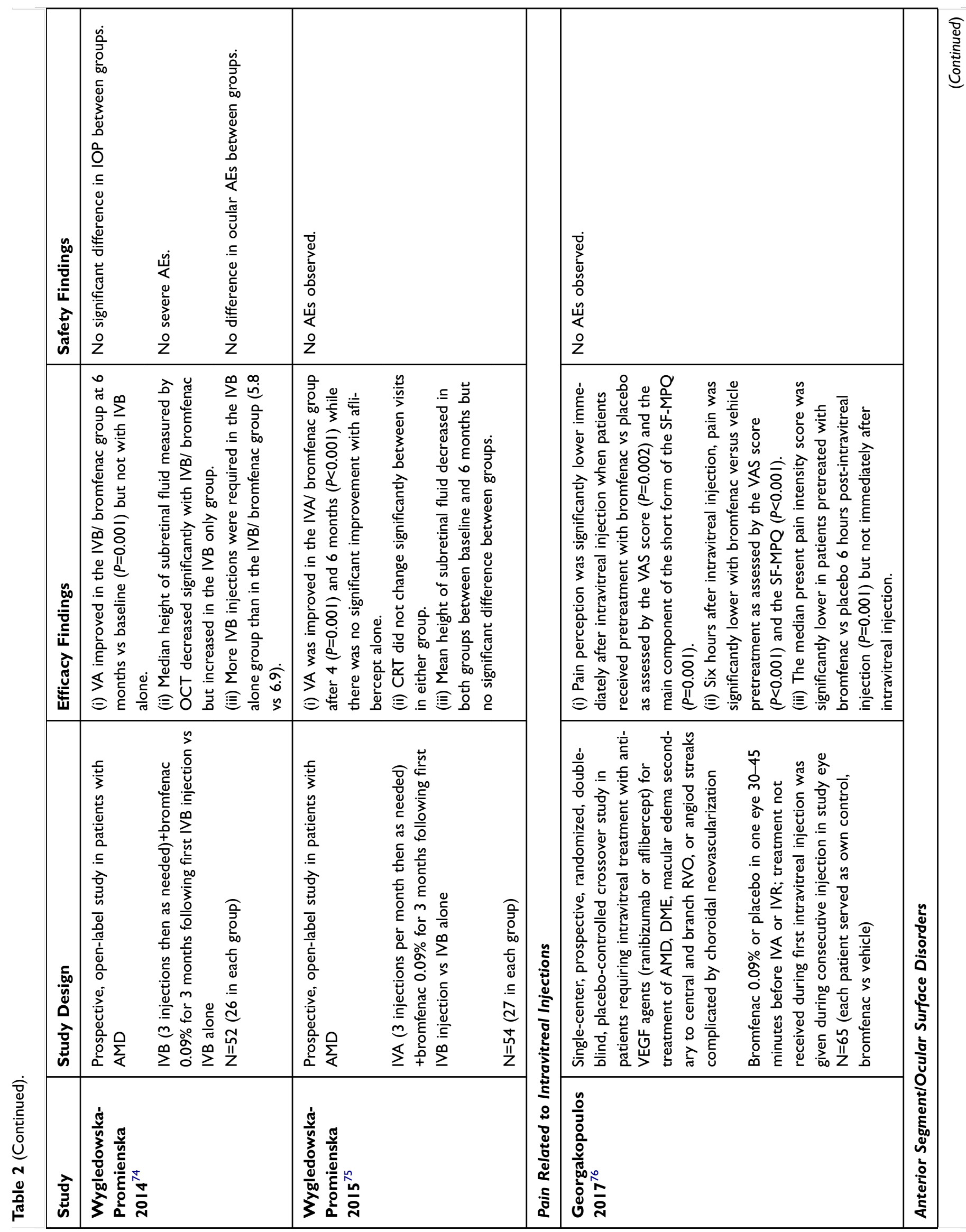




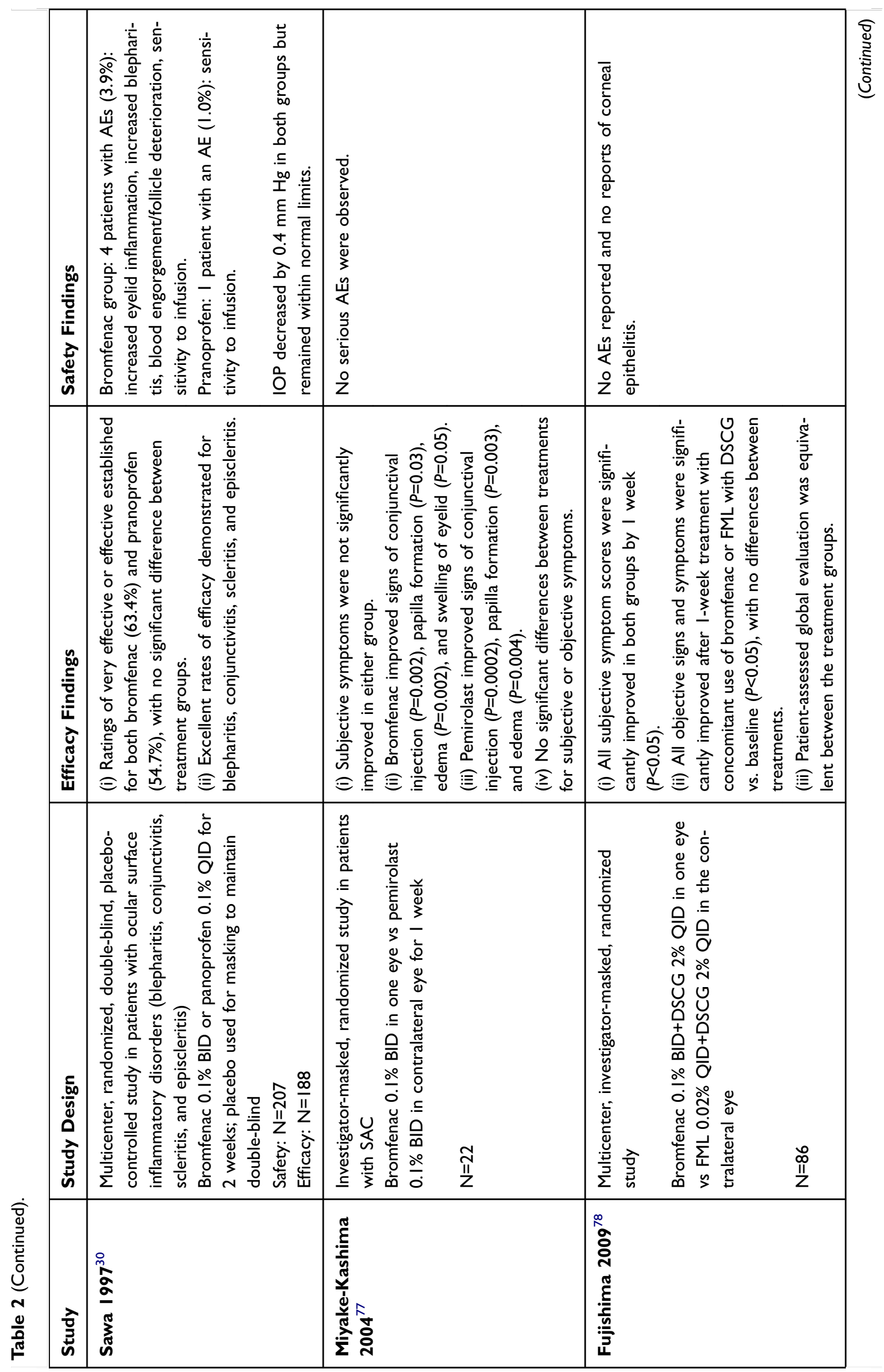




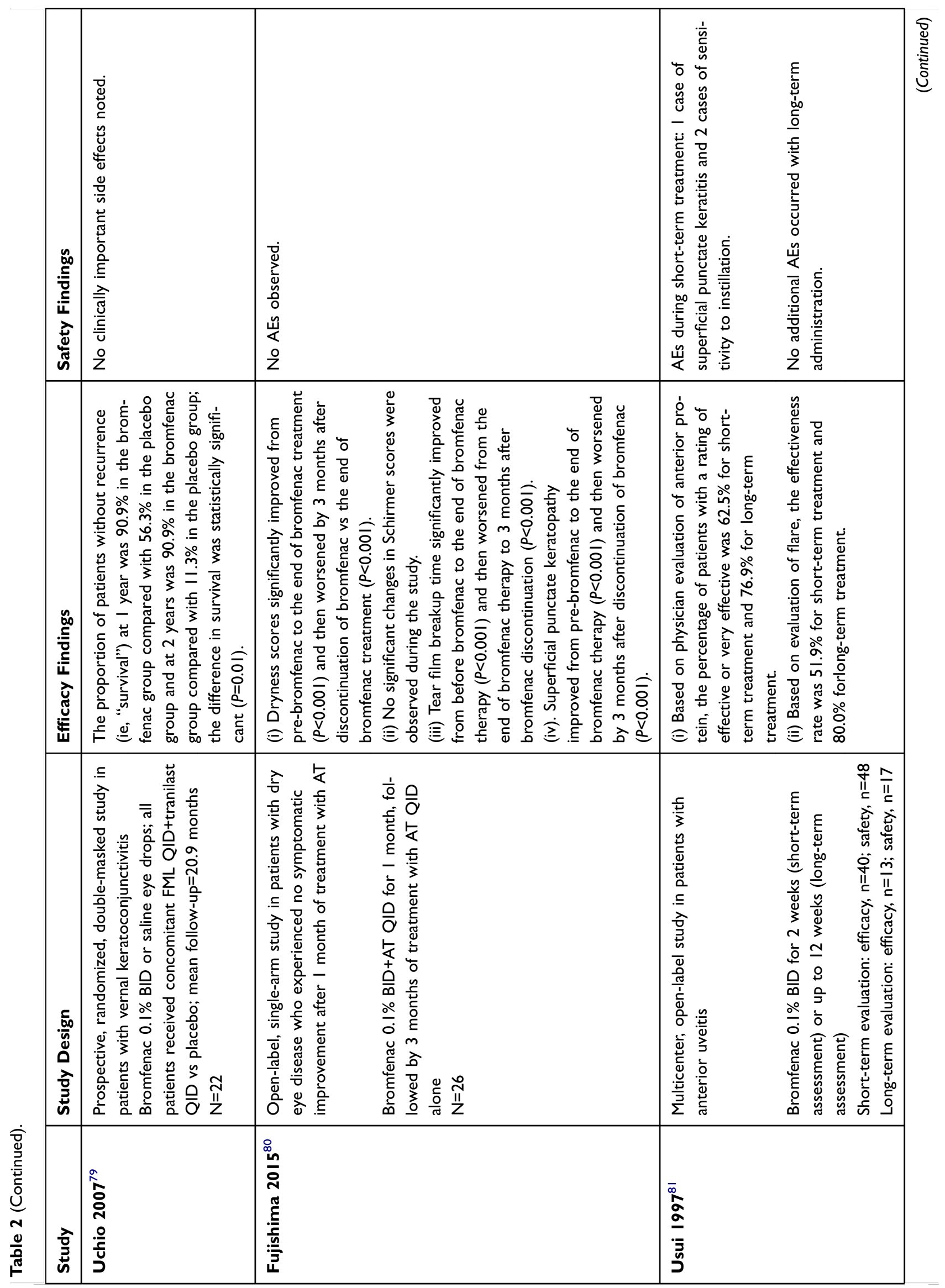




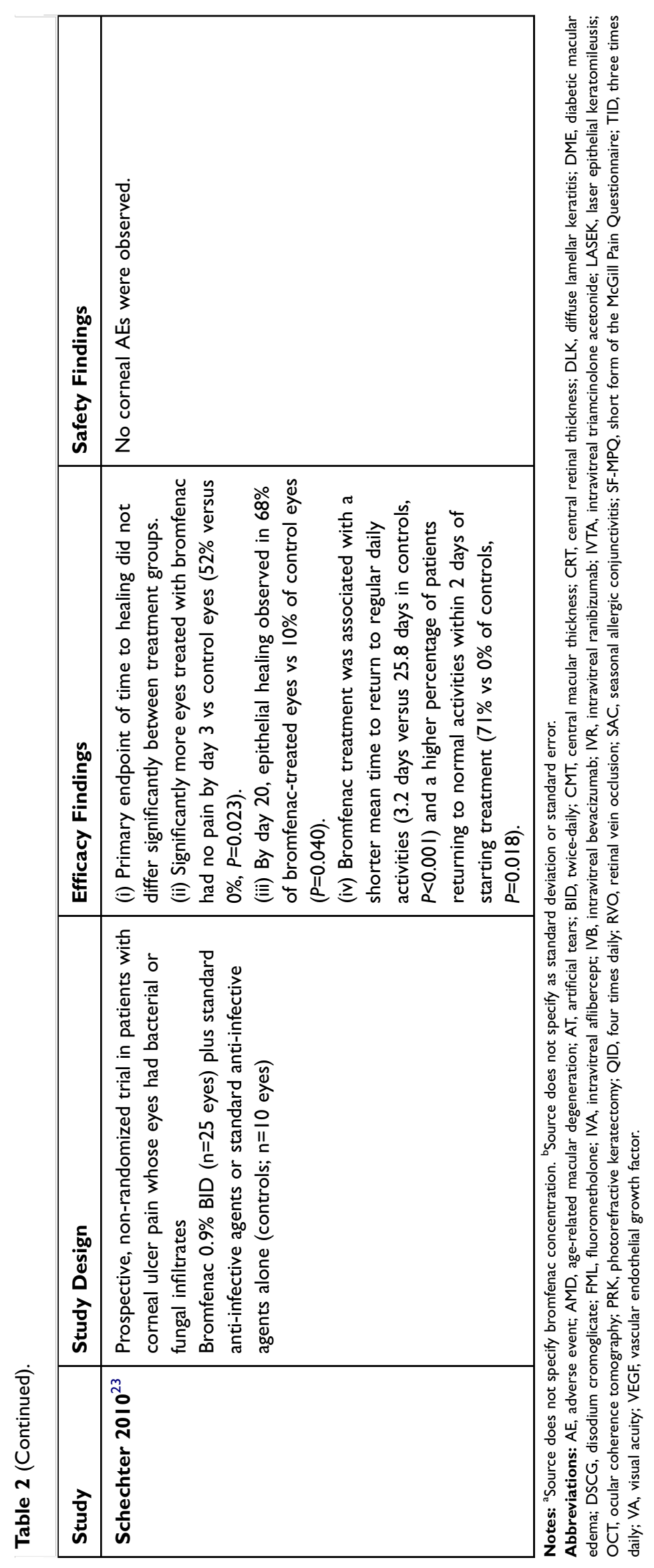


suggested that this could have been a consequence of their study procedures, which included removing the bandage contact lens (BCL) and application of a drop of fluorescein sodium ophthalmic solution $1 \%$ at each postoperative visit. Physical manipulation of the BCL and application of fluorescein, which is known to be toxic to epithelial cells, may have delayed reepithelialization. Moreover, the concurrent use of different antibiotics (moxifloxacin 0.5\% in nepafenac eyes and gatifloxacin $0.3 \%$ in all other eyes) along with differences in sample size may have confounded study results further. Nevertheless, there were no AEs reported and no evidence of corneal toxicity in any treatment group.

An open-label study compared the use of topical bromfenac $0.09 \%$ BID ( $\mathrm{n}=105$ eyes) with ketorolac 0.4\% QID $(\mathrm{n}=107$ eyes), each given postoperatively until epithelial healing occurred, for management of pain, discomfort, and photophobia following PRK. ${ }^{65}$ Patients undergoing unilateral surgery were randomly assigned to a treatment group; those having surgery on both eyes used one treatment in each eye. Following placement of a BCL on the operated eye, all patients received their assigned NSAID in addition to prednisolone acetate $1 \%$ eye drops and gatifloxacin $0.3 \%$ ophthalmic solution. No significant differences were noted with regard to postoperative pain, burning, foreign body sensation, photophobia, or epithelial healing rate between the two treatment groups at any time point, with defects fully resolved in both groups at day 5. There were no AEs that were considered related to either treatment.

Bromfenac 0.09\% BID and ketorolac 0.5\% QID were compared in patients undergoing LASEK $(n=32)$ or epiLASEK $(n=8)$ in a prospective, randomized study. ${ }^{66}$ For each patient, the right eye was randomized to either bromfenac or ketorolac, and the left eye was treated with the alternate NSAID. One drop of study medication was instilled in each eye 15 mins prior to surgery and 2 and $4 \mathrm{hrs}$ after surgery, then patients were instructed to instill one drop QID for 4 days. For masking purposes, numbered eye-specific medication vials were provided to patients such that two of the daily bromfenac group instillations were AT. Patient-rated pain scores for the bromfenac-treated eyes were lower as compared to ketorolactreated eyes on the day of surgery and every day through 4 days postsurgery $(P<0.01$ at each time point). Scores for visual blurriness were not statistically different between treatments at any time point. Epithelial healing was complete by day 6 for all eyes. Overall, AEs were similar between treatment groups; eight patients (20\%) reported temporary dry eye in both eyes, and two patients $(5 \%)$ reported temporary irritation in both eyes.

Overall, these studies suggest that bromfenac provides relief of pain and discomfort similar to that of other topical anti-inflammatories without apparent adverse consequences in patients following refractive eye surgery. While most studies comparing bromfenac with ketorolac reported no difference in epithelial healing rate, one study reported a shorter time to reepithelialization with nepafenac or ketorolac compared with bromfenac.

\section{Macular edema associated with uveitis, diabetes, and retinal vein occlusion (RVO)}

Macular edema is a build-up of fluid in the macula that can develop secondary to a number of conditions, including uveitis or as a complication of diabetes or branch RVO. ${ }^{83}$ Prostaglandins can contribute to the process by causing vasodilation and partial disruption of the blood-ocular barrier. ${ }^{84,85}$ Macular edema can result in impairment of central vision and is a significant cause of vision loss in patients with metabolic, vascular, and inflammatory retinal diseases. Treatment of macular edema typically includes topical antiinflammatory agents, including corticosteroids or NSAIDs. ${ }^{86,87}$ Inhibitors of VEGF are also often employed since VEGF has been implicated in the pathogenesis of macular edema via multiple mechanisms. ${ }^{87}$ The potential benefits of NSAIDs in macular edema relate to their ability to inhibit COX-2, resulting in reduced production of prostaglandins, although additional mechanisms of action have been proposed, including effects on leukotriene formation and modulation of chloride movement, thus affecting fluid movement through the retinal pigment epithelium. ${ }^{87}$ Additionally, NSAIDs may downregulate VEGF via inhibition of COX-2 activity, ${ }^{1,88}$ and this mechanism of action may potentially contribute to the beneficial effects of NSAIDs in treating macular edema. The ability of topically applied NSAIDs to achieve therapeutic levels in the retina is relevant to the treatment of macular edema. ${ }^{6}$ A 2015 Cochrane Database systematic review did not identify any randomized, controlled trials of NSAIDs ongoing or completed studies for the treatment of diabetic $\mathrm{CME}^{89}$

Three studies have evaluated the use of topical bromfenac alone or administered adjunctively with other medications in the treatment of macular edema (Table 2). A pilot study evaluated the effect of bromfenac $0.09 \%$, instilled BID for 30 days in the affected eye, in 17 patients 
with newly diagnosed diabetic macular edema (DME). ${ }^{68}$ Mean central macular thickness (CMT) decreased from a baseline of 465.41 to $388.88 \mu \mathrm{m}(P=0.02)$. Macular volume and best corrected VA did not change significantly over the course of the study, although there was a trend toward reduced macular volume $(P=0.06)$. Bromfenac was well tolerated and no AEs were reported.

A retrospective, comparative case series compared outcomes among patients with uveitic macular edema who were treated with either bromfenac BID monotherapy $(n=34)$, bromfenac BID in combination with a single intravitreal injection of bevacizumab (IVB) $(n=21)$, or bromfenac BID in combination with a single intravitreal injection of triamcinolone (IVTA) ( $\mathrm{n}=12) .{ }^{69}$ Change (improvement) from baseline in VA (primary outcome) was noted in all treatment groups at 3 months, but was only significant for the bromfenac/IVB and bromfenac/IVTA groups $(P \leq 0.017)$. Likewise, CMT decreased in all groups, but only significantly in the bromfenac/IVB and bromfenac/IVTA groups $(P \leq 0.009)$. It should be noted that mean baseline CMT was significantly $(P=0.018)$ higher in the IVB and IVTA treatment groups vs the bromfenac monotherapy group; further, baseline mean VA was numerically lower (better) in the bromfenac monotherapy group, suggesting that the patients treated with IVB and IVTA were more severe and likely to demonstrate greater changes from baseline. Mean VA scores at 3 months were similar in the bromfenac monotherapy, bromfenac/IVB, and bromfenac IVTA groups $(0.31,0.35,0.33$, respectively; $P=0.928)$.

The efficacy of bromfenac $0.1 \%$ in combination with IVB in 44 patients (48 eyes) with macular edema related to branch RVO was studied in a prospective case-control pilot study. ${ }^{70}$ Patients received IVB initially and repeated the treatment when macular edema (defined as foveal thickness $\geq 300 \mu \mathrm{m}$ ) recurred. Prior to the second IVB injection, patients were randomized to treatment with topical bromfenac QID ( $\mathrm{n}=24$ eyes) or AT QID ( $\mathrm{n}=24$ eyes) for 48 weeks. On average, patients in the bromfenac group required fewer injections (mean $\pm \mathrm{SD}$ : $3.8 \pm 1.1$ ) of IVB than those in the saline group (mean $\pm \mathrm{SD}: 4.8 \pm 1.2$ ) throughout their clinical course $(P=0.014)$. However, no significant differences in foveal thickness or VA were observed between bromfenac- and saline-treated eyes. There were no reported AEs related to bromfenac administration.

Overall, these small studies indicate that bromfenac may be of benefit alone in patients with DME or in conjunction with intravitreal corticosteroids/VEGF inhibitors for the treatment of uveitic macular edema or with VEGF inhibitors for the treatment of macular edema associated with RVO. Further investigation through more robust, controlled studies are necessary to evaluate the role of bromfenac monotherapy and combination regimens with corticosteroids or VEGF inhibitors in these conditions.

\section{Inflammation associated with AMD}

AMD is a leading cause of blindness worldwide. $^{90}$ Intravitreal injections of anti-VEGF agents such as bevacizumab and ranibizumab are commonly used to treat neovascular (wet) AMD. ${ }^{91}$ As inflammation plays an important role in AMD, the adjunctive use of topical NSAIDs has been studied in these patients. ${ }^{26}$ Possible mechanisms of action of NSAIDs in AMD include a reduction of inflammation and edema and minimization of COX-2-facilitated choroidal neovascularization. ${ }^{72,92}$ Further, studies suggest that COX-2 promotes angiogenesis by modulating the expression of the VEGF receptor and thus inhibition of COX-2 is thought to downregulate VEGF. ${ }^{1,88}$ Topical administration of NSAIDs for the treatment of AMD has several potential benefits, including minimal risk of complications/adverse effects and achievement of therapeutic levels in the retina.,72

One retrospective case series and four prospective studies have evaluated bromfenac in combination with anti-VEGF agents in patients with AMD (Table 2). A retrospective case series compared 30 patients receiving intravitreal ranibizumab (IVR) for the treatment of choroidal neovascular membrane associated with neovascular AMD with 30 patients who received IVR in combination with bromfenac $0.09 \%$ BID over a period of 6 months. ${ }^{71}$ The addition of bromfenac significantly reduced the number of ranibizumab injections required to control choroidal neovascular membrane (1.6 \pm 0.69 vs $4.5 \pm 0.41$, $P=0.0002)$. Improvement in VA did not differ between the two treatment regimens, and similar trends were observed for optical coherence tomography (OCT) and fluorescein angiography data. Extended topical administration of bromfenac was not associated with any AEs.

An open-label pilot study evaluated the addition of bromfenac $0.09 \%$ BID for 12 months to treatment with IVR (administered monthly for 4 months, then monthly as needed) in patients with wet AMD. ${ }^{72}$ Patients who received combination therapy $(n=20)$ were compared with those who received IVR alone $(n=10)$. There were no significant differences between treatment groups in baseline characteristics, including CMT, VA, number of patients with newly diagnosed exudative AMD, and lesion type. In both groups, there was a significant reduction 
from baseline in CMT at 12 months $(P<0.005)$. Compared with monotherapy, combination treatment with bromfenac plus IVR was associated with a greater mean reduction in CMT at 12 months $(-81.56 \mu \mathrm{M}$ vs $-42.50 \mu \mathrm{M}, P=0.03)$. Further, the proportion of eyes experiencing clinically relevant improvement $(>50 \mu \mathrm{m}$ decrease in CMT) was greater for the combination group $(P=0.046)$. There were no significant differences between treatment groups in the number of IVR injections received and no significant changes in VA between study groups at any time point. The overall frequency of ocular AEs, all mild in severity, was similar between treatment groups, although reports of burning/stinging occurred more often among patients receiving bromfenac.

A single-center, randomized, double-masked, placebocontrolled study evaluated topical bromfenac in patients with AMD with lesions $<2$ disk diameters. ${ }^{73}$ Patients were randomized $2: 3$ to receive either topical bromfenac sodium $0.1 \%$ $(n=16)$ or AT BID $(n=22)$ for 6 months in addition to at least one 0.5 -mg IVR injection. Additional IVR injections were administered if there was evidence of intraretinal or subretinal fluid in the macula at visits at 3 and 6 months. The mean \pm SD number of IVR injections required over 6 months was lower in the bromfenac group (2.2 \pm 1.3$)$ versus the AT group ( $3.2 \pm 1.5$; $P=0.027)$. Change in VA did not differ between groups $(P=0.314)$, while a nonsignificant $(P=0.060)$ trend toward a reduction in central retinal thickness in the bromfenac group was observed. One patient in the AT group discontinued treatment due to an unpleasant sensation.

In a prospective open-label study, patients with exudative AMD were treated with topical bromfenac $0.09 \%$ and IVB injections $(\mathrm{n}=26)$ or IVB injections alone $(\mathrm{n}=26){ }^{74}$ Both groups received three initial IVB injections, with additional injections given each time an increase in subretinal fluid was noted on OCT examination. In the combination treatment group, bromfenac was administered BID for 3 months beginning after the first dose of IVB. At 6 months, VA improved significantly compared to baseline in the bromfenac group $(P=0.001)$ but not in the group that received IVB alone. More IVB injections were required in the IVB-alone group than in the IVB+bromfenac group (5.8 [95\% CI, 4.5-6.5] vs 6.9 [95\%, 5.0-8.0). All AEs were mild or moderate in severity with no difference in the overall incidence of ocular AEs between treatment groups. Similar results were observed in a study by the same authors with similar methodology, except the intravitreal injections comprised aflibercept (IVA). ${ }^{75}$ While VA improved significantly from baseline in the
bromfenac+IVA group $(\mathrm{n}=27)$ after 4 months $(P=0.001)$ and 6 months $(P<0.001)$, there was no significant improvement in the group managed with IVA alone $(n=27)$. Central retinal thickness did not change significantly between visits in either group. Median height of subretinal fluid (in $\mu \mathrm{m}$ ) on OCT decreased in both treatment groups between baseline and 6 months but was not significantly different between groups. No AEs were observed.

In summary, the adjunctive use of bromfenac for the treatment of AMD has demonstrated some clinical benefits compared with anti-VEGF therapy alone with no apparent safety issues. In some studies, the use of bromfenac led to a significant reduction in the number of intravitreal antiVEGF injections required.

\section{Pretreatment for pain related to intravitreal injections}

Intravitreal injection is an invasive procedure that may cause pain during and after injections, which may contribute to pre-procedural anxiety. ${ }^{93}$ Topical NSAIDS, including ketorolac and nepafenac, have been shown to reduce ocular pain during and/or after intravitreal injections. ${ }^{76,94,95}$

A single-center, prospective, randomized, double-blind, placebo-controlled crossover study evaluated the efficacy and safety of pretreatment with bromfenac for pain in 65 patients requiring intravitreal injections with an anti-VEGF agent (Table 2) ${ }^{76}$ Patients in this study were receiving IVR or IVA for the treatment of AMD, DME, macular edema secondary to central and branch RVO, or angioid streaks complicated by choroidal neovascularization. A single drop of bromfenac $0.09 \%$ or placebo (AT) was administered topically into one eye $30-45$ mins before IVA or IVR; patients crossed over to receive the alternative treatment (bromfenac or placebo) during the next consecutive injection of IVR or IVA. Immediately after intravitreal injection, pain perception was significantly lower following pretreatment with bromfenac vs placebo based on both the visual analogue scale (VAS)score $(P=0.002)$ and the main component of the short form of the McGill Pain Questionnaire (SF-MPQ; $P=0.001$ ). Similarly, at 6 hrs post-intravitreal injection, bromfenac treatment was associated with significantly lower pain scores compared with placebo on the VAS and the SF-MPQ $(P<0.001$ for both comparisons). The median pain intensity score was significantly lower in patients pretreated with bromfenac compared with placebo $6 \mathrm{hrs}$ post-intravitreal injection $(P=0.001)$ but not immediately after intravitreal injection. No AEs were observed 
during the study. These findings suggest that topical bromfenac may have a beneficial effect in reducing postinjection pain for up to $6 \mathrm{hrs}$ following intravitreal injection.

\section{Inflammation associated with ocular anterior segment/surface disorders}

A number of ocular anterior segment and surface disorders have an inflammatory component and thus topical NSAIDs may be a suitable treatment option for these conditions. ${ }^{96-98}$ Accordingly, topical NSAIDs have been found to be effective in patients with SAC, ${ }^{27-29,99-101}$ vernal keratoconjunctivitis, ${ }^{31,32}$ acute anterior uveitis, ${ }^{102}$ and dry eye disease. ${ }^{33}$ Bromfenac has been evaluated for a variety of anterior segment and ocular surface disorders, including blepharitis, SAC, vernal keratoconjunctivitis, scleritis and episcleritis, dry eye disease, anterior uveitis, and corneal ulcer pain (Table 2).

A multicenter, randomized, double-masked study compared bromfenac $0.1 \%$ BID with pranoprofen $0.1 \%$ QID, administered over 2 weeks, in Japanese patients with a range of ocular surface inflammatory disorders, including blepharitis, conjunctivitis, corneal inflammation, scleritis, and episcleritis. ${ }^{30}$ Placebo was used to mask assignment to bromfenac vs pranoprofen. Efficacy was evaluated in 188 patients (bromfenac, $\mathrm{n}=93$; pranoprofen, $\mathrm{n}=95$ ) and safety in 207 patients (bromfenac, $\mathrm{n}=102$; pranoprofen, $\mathrm{n}=105$ ). Patients were assessed prior to instillation and on days 3, 7, and 14, and after treatment. For the entire population, good efficacy (ratings of "very effective" or "effective" based on a scoring system incorporating clinical observations and subjective/objective symptom scores) was reported for $63.4 \%$ (59/93) of bromfenac-treated patients and 54.7\% (52/95) of pranoprofen-treated patients, with no significant difference between treatment groups. Both treatment groups showed excellent rates of efficacy for blepharitis, conjunctivitis, scleritis, and episcleritis, whereas the number of cases was too small for complete evaluation of efficacy for corneal inflammation. Four AEs (incidence of 3.9\%) were reported in the bromfenac group (increased eyelid inflammation, increased blepharitis, blood engorgement/follicle deterioration, sensitivity to infusion), and one $\mathrm{AE}$ was reported in the pranoprofen group (1.0\%; sensitivity to infusion).

Two published studies have evaluated bromfenac in patients with SAC. A Japanese study compared bromfenac $0.1 \%$ BID to the topical mast-cell stabilizer pemirolast $0.1 \%$ BID in 22 patients with a minimum 1-year history of SAC. ${ }^{77}$ Each patient instilled one of the study medications in one eye and the other study medication in the contralateral eye for 1 week. As evaluated by masked investigators, both drugs significantly improved conjunctival injection, papilla formation, and edema at 1 week $(P<0.05$ for all comparisons). Neither drug significantly improved subjective symptoms (itching, lacrimation, ocular discharge, redness, nasal discharge) and there were no significant differences between treatments in either subjective or objective symptoms.

A 1-week multicenter, randomized, investigatormasked study compared bromfenac $0.1 \%$ BID to fluorometholone $0.02 \%$ QID in 86 patients with SAC. $^{78}$ All patients used the mast-cell stabilizer disodium cromoglicate $2 \%$ QID in both eyes and were randomized to additional treatment with either bromfenac or fluorometholone in the right eye and the other study medication in the left eye. After 1 week of treatment, conjunctival itching, lacrimation, discharge, foreign body sensation, and conjunctival injection were significantly improved from baseline in both groups $(P<0.05)$. There were no significant differences between treatments. No treatment-related AEs were observed, and there were no reports of corneal epithelitis.

A randomized, double-masked, placebo-controlled study evaluated long-term use of bromfenac $0.1 \%$ BID as adjunctive therapy to fluorometholone QID and the mast-cell stabilizer tranilast QID in 22 patients (21 males, 1 female; mean age 14.5 years; range, 4-34 years) with vernal keratoconjunctivitis, an allergic ocular condition typically seen in young boys and in countries with a warm climate. ${ }^{79}$ Patients were randomized to receive bromfenac $0.1 \%$ $(n=11)$ or placebo (normal saline eye drops, $n=11)$ BID. Patients used weekly diary cards to record severity of symptoms on a scale from 0 (none) to 3 (severe). Investigator assessments of disease severity (clinical assessment and slit lamp evaluation) were performed at clinic visits at months 1,2 , and 4, then approximately every 3 months thereafter. Clinical recurrence was defined as an increase of three or more points in the "clinical score," defined as the total score for three subjective (itching, eye discharge, photophobia) and seven objective (conjunctival hyperemia, chemosis, follicles, giant papillae, limbal edema, Trantas' dots, corneal lesions) findings. Mean duration of follow-up was 18.7 months in the bromfenac group and 23.7 months in the placebo group. A greater proportion of patients receiving bromfenac vs placebo eye drops were without clinical recurrence (ie, "survived") at 1 year (90.9\% vs $56.3 \%)$ and at 2 years $(90.9 \%$ vs $11.3 \%)$; the difference 
in survival was statistically significant $(P=0.01)$. No clinically important AEs were observed.

An open-label study evaluated the effect of adding bromfenac $0.1 \%$ to AT on signs and symptoms of dry eye in 26 Japanese patients who experienced no symptomatic improvement after 1 month of AT alone. ${ }^{80}$ Bromfenac BID was administered along with AT QID for 1 month, with AT treatment alone continued for the subsequent 3 months. Dryness scores at the end of bromfenac treatment were significantly improved versus pre-bromfenac scores $(P<0.001)$ as well as dryness scores 3 months after discontinuation of bromfenac treatment $(P<0.001)$. While no significant changes in Schirmer scores were observed during the study, the tear film breakup time (BUT) was significantly improved at the end of bromfenac therapy (mean \pm SD: $4.4 \pm 2.3 \mathrm{~s}$ ) compared with before initiation of bromfenac (mean \pm SD: $2.8 \pm 1.8 \mathrm{~s}, P<0.001$ ); BUT declined significantly from the end of bromfenac therapy to 3 months after bromfenac discontinuation $(P<0.001)$. Similarly, superficial punctate keratopathy improved significantly from pre-bromfenac to the end of bromfenac therapy $(P<0.001)$ and then worsened by 3 months after discontinuation of bromfenac $(P<0.001)$. No AEs were reported.

A multicenter, open-label Japanese study assessed bromfenac $0.1 \%$ BID for the treatment of anterior uveitis. ${ }^{81}$ Both short-term ( 2 weeks; efficacy, $n=40$; safety, $n=48$ ) and long-term (12 weeks; efficacy, $\mathrm{n}=13$; safety, $\mathrm{n}=17$ ) administration were evaluated; patients continued treatment for up to 12 weeks if the investigator determined that control of inflammation was possible or necessary through continued administration of bromfenac. The percentage of patients with a rating of effective or very effective based on physician evaluation of anterior protein was $62.5 \%$ for short-term treatment and $76.9 \%$ for long-term treatment. The effectiveness rate based on evaluation of flare was $51.9 \%$ for shortterm treatment and $80.0 \%$ for long-term treatment. During short-term treatment with bromfenac, AEs included one case of superficial punctate keratitis and two cases of sensitivity to instillation. No additional AEs occurred with longterm administration.

Bromfenac has also been evaluated for the treatment of corneal ulcer pain in a prospective, non-randomized trial. ${ }^{23}$ Eyes with bacterial or fungal infiltrates were treated either with bromfenac $0.9 \%$ BID ( $\mathrm{n}=25$ eyes) plus standard antiinfective agents or with standard anti-infective agents alone (controls; $\mathrm{n}=10$ eyes). Although the primary endpoint of time to healing did not differ significantly between treatment groups, significantly more eyes treated with bromfenac had no pain by day 3 compared with control eyes $(52 \%$ vs $0 \%, P=0.023)$. The epithelium of bromfenac-treated eyes was also more likely to have healed by day $20(68 \%$ vs $10 \%$ of control eyes, $P=0.040)$. Additionally, bromfenac was associated with significant functional improvement, reflected by a shorter mean time to return to regular daily activities (3.2 days vs 25.8 days in controls, $P<0.001)$ and a higher percentage of patients returning to normal activities within 2 days of starting treatment ( $71 \%$ vs $0 \%$ of controls, $P=0.018)$. Bromfenac treatment was not associated with any corneal AEs, although larger studies are needed to establish the safety of bromfenac in this patient population. It should also be noted that NSAIDs may cause sterile corneal ulcers with continued use, especially in at-risk patients. ${ }^{10}$

Results of these studies suggest that bromfenac may have benefits across a range of anterior segment and ocular surface disorders. In all studies, bromfenac was well tolerated with no clinically important side effects reported. It should be noted that use of bromfenac and other topical NSAIDs has been associated with adverse corneal sequelae such as corneal erosions, ulceration, and perforation, particularly in patients considered high risk (complicated oral surgeries, corneal denervation, corneal epithelial defects, diabetes mellitus, ocular surface diseases, rheumatoid arthritis, repeat ocular surgeries within a short time) and those treated with prolonged use after ( $>14$ days) or before ( $>24 \mathrm{hrs}$ ) surgery. ${ }^{10}$

\section{Summary}

Topical NSAIDs, while generally approved for management of postsurgical pain and inflammation following cataract surgery, are increasingly being investigated for their utility in other ocular conditions with an inflammatory component. The evidence reviewed here supports the safety and efficacy of bromfenac for a number of indications other than its approved indication (treatment of post-cataract surgery inflammation and pain) or the non-approved but clinically well-established use for prevention of post-cataract surgery CME. Several studies have demonstrated that bromfenac decreases eye pain and irritative symptoms following refractive surgery with no signals for increased rates of side effects or adverse changes in VA or healing/corneal epithelialization. ${ }^{61-66}$ Bromfenac has shown promise in reducing retinal thickening in patients with DME and has been reported to be beneficial in the management of uveitic macular edema when used in combination with IVTA or IVB including improvements in CMT and $\mathrm{VA}^{69}$ and 
reduced frequency of intravitreal injections. ${ }^{70}$ Results of several studies suggest that topical bromfenac may be beneficial in patients with anterior segment and/or inflammatory ocular surface disorders, including blepharitis, ${ }^{30}$ conjunctivitis/SAC/vernal keratoconjunctivitis, scleritis/ episcleritis, ${ }^{30,77-79}$ dry eye disease,${ }^{80}$ anterior uveitis, ${ }^{81}$ and corneal ulcer pain. ${ }^{23}$

The studies reviewed herein demonstrated that bromfenac was well tolerated when given alone or in combination with intravitreal anti-VEGF agents, topical corticosteroids, or topical mast-cell stabilizers, with the most common AEs being signs of irritation. Corneal complications have been reported with NSAIDs (particularly diclofenac, ketorolac) ${ }^{103,104}$ but were not reported in these reviewed studies. Overall, these findings are consistent with the generally good safety profile of topical ophthalmic NSAIDs. ${ }^{104}$

In conclusion, a growing body of research suggests the potential utility of the topical NSAID bromfenac for various ocular disorders. Additional studies are warranted to further define the potential role of bromfenac ophthalmic solution in clinical practice.

\section{Acknowledgments}

The author expresses his appreciation to Megan Cavet, $\mathrm{PhD}$ of Bausch + Lomb, a division of Bausch Health US, LLC for her expertise in reviewing and editing the manuscript. The author acknowledges the writing assistance of Churchill Communications (Maplewood, NJ), funded by Bausch + Lomb.

\section{Disclosure}

The author reports no conflicts of interest in this work.

\section{References}

1. Kim SJ, Flach AJ, Jampol LM. Nonsteroidal anti-inflammatory drugs in ophthalmology. Surv Ophthalmol. 2010;55(2):108-133. doi:10.1016/j.survophthal.2009.07.005

2. Flach AJ. Topical nonsteroidal antiinflammatory drugs in ophthalmology. Int Ophthalmol Clin. 2002;42(1):1-11. doi:10.1097/00004397200201000-00003

3. Lindstrom R. The pharmacologic and pathophysiologic rationale for using NSAIDs in ocular inflammatory disease and ocular surgery. Int Ophthalmol Clin. 2006;46(4):7-11. doi:10.1097/01.iio.0000212131. 98760.a9

4. Ahuja M, Dhake AS, Sharma SK, Majumdar DK. Topical ocular delivery of NSAIDs. Aaps J. 2008;10(2):229-241. doi:10.1208/ s12248-007-9006-3

5. Farah AE, Rosenberg F. Potential therapeutic applications of aspirin and other cyclo-oxygenase inhibitors. Br J Clin Pharmacol. 1980;10 (Suppl 2):261S-278S. doi:10.1111/j.1365-2125.1980.tb01809.x
6. Schoenberger SD, Kim SJ. Nonsteroidal anti-inflammatory drugs for retinal disease. Int J Inflam. 2013;2013:281981. doi:10.1155/ 2013/281981

7. Chen H. Recent developments in ocular drug delivery. J Drug Target. 2015;23(7-8):597-604. doi:10.3109/1061186X.2015.1052073

8. Acuvail [package Insert]. Irvine, CA: Allergan, Inc.; 2014.

9. Ilevro [package insert]. Fort Worth, TX: Alcon Laboratories, Inc.; 2014.

10. Prolensa [package insert]. Tampa, FL: Bausch and Lomb Inc.; 2013.

11. Voltaren [package insert]. Fort Worth, TX: Alcon Laboratories, Inc.; 2012.

12. Acular [package insert]. Irvine, CA: Allergan, Inc.; 2012.

13. Wilson DJ, Schutte SM, Abel SR. Comparing the efficacy of ophthalmic NSAIDs in common indications: a literature review to support cost-effective prescribing. Ann Pharmacother. 2015;49 (6):727-734. doi:10.1177/1060028015574593

14. Rodrigues EB, Farah ME, Bottós JM, Bom Aggio F. Nonsteroidal anti-inflammatory drugs in the treatment of retinal diseases. Dev Ophthalmol. 2016;55:212-220.

15. Seth A, Ghosh B, Raina UK, Gupta A, Arora S. Intravitreal diclofenac in the treatment of macular edema due to branch retinal vein occlusion. Ophthalmic Surg Lasers Imaging Retina. 2016;47 (2):149-155. doi:10.3928/23258160-20160126-08

16. Appiotti A, Gualdi L, Alberti M, Gualdi M. Comparative study of the analgesic efficacy of flurbiprofen and diclofenac in patients following excimer laser photorefractive keratectomy. Clin Ther. 1998;20(5):913-920.

17. Kim SK, Hong JP, Nam SM, Stulting RD, Seo KY. Analgesic effect of preoperative topical nonsteroidal antiinflammatory drugs on postoperative pain after laser-assisted subepithelial keratectomy. J Cataract Refract Surg. 2015;41(4):749-755. doi:10.1016/j.jcrs.2014.06.041

18. Mohammadpour M, Jabbarvand M, Nikdel M, Adelpour M, Karimi N. Effect of preemptive topical diclofenac on postoperative pain relief after photorefractive keratectomy. J Cataract Refract Surg. 2011;37(4):633-637. doi:10.1016/j.jcrs.2010.10.040

19. Sher NA, Frantz JM, Talley A, et al. Topical diclofenac in the treatment of ocular pain after excimer photorefractive keratectomy. Refract Corneal Surg. 1993;9(6):425-436.

20. Solomon KD, Donnenfeld ED, Raizman M, et al; On behalf of Ketorolac Reformulation Study Groups 1 and 2. Safety and efficacy of ketorolac tromethamine $0.4 \%$ ophthalmic solution in post-photorefractive keratectomy patients. J Cataract Refract Surg. 2004;30 (8):1653-1660. doi:10.1016/S0886-3350(03)00497-8.

21. Tutton MK, Cherry PM, Raj PS, Fsadni MG. Efficacy and safety of topical diclofenac in reducing ocular pain after excimer photorefractive keratectomy. J Cataract Refract Surg. 1996;22(5):536541. doi:10.1016/S0886-3350(96)80005-8

22. Weinstock VM, Weinstock DJ, Weinstock SJ. Diclofenac and ketorolac in the treatment of pain after photorefractive keratectomy. $J$ Refract Surg. 1996;12(7):792-794.

23. Schechter BA, Trattler W. Efficacy and safety of bromfenac for the treatment of corneal ulcer pain. Adv Ther. 2010;27(10):756-761. doi:10.1007/s12325-010-0066-x

24. Mohammadpour M, Heidari Z, Molani R. Comparison between diclofenac and ketorolac ophthalmic drops for pain management after photorefractive keratectomy: a randomized clinical study. Eye Contact Lens. 2019;45(2):137-140. doi:10.1097/ICL.0000000000000524

25. Hong JP, Nam SM, Im CY, et al. Comparison of analgesic effect of preoperative topical diclofenac and ketorolac on postoperative pain after photorefractive keratectomy. J Cataract Refract Surg. 2014;40 (10):1689-1696. doi:10.1016/j.jcrs.2014.05.029

26. Li S, Hu A, Wang W, Ding X, Lu L, Jablonski MM. Combinatorial treatment with topical NSAIDs and anti-VEGF for age-related macular degeneration, a meta-analysis. PLoS One. 2017;12(10): e0184998. doi:10.1371/journal.pone.0184998 
27. Tinkelman DG, Rupp G, Kaufman H, Pugely J, Schultz N. Double-masked, paired-comparison clinical study of ketorolac tromethamine $0.5 \%$ ophthalmic solution compared with placebo eyedrops in the treatment of seasonal allergic conjunctivitis. Surv Ophthalmol. 1993;38 Suppl:133-140. doi:10.1016/00396257(93)90037-8

28. Tauber J, Raizman MB, Ostrov CS, et al. A multicenter comparison of the ocular efficacy and safety of diclofenac $0.1 \%$ solution with that of ketorolac $0.5 \%$ solution in patients with acute seasonal allergic conjunctivitis. J Ocul Pharmacol Ther. 1998;14(2):137145. doi:10.1089/jop.1998.14.229

29. Swamy BN, Chilov M, McClellan K, Petsoglou C. Topical nonsteroidal anti-inflammatory drugs in allergic conjunctivitis: metaanalysis of randomized trial data. Ophthalmic Epidemiol. 2007;14 (5):311-319. doi:10.1080/09286580701344399

30. Sawa M, Masuda K, Usui M, Komemushi S. Efficacy of $0.1 \%$ bromfenac sodium ophthalmic solution for ocular surface inflammation: a double-masked controlled trial. Folia Ophthalmol Jpn. 1997;48(5):717-724.

31. Sharma A, Gupta R, Ram J, Gupta A. Topical ketorolac 0.5\% solution for the treatment of vernal keratoconjunctivitis. Indian $J$ Ophthalmol. 1997;45(3):177-180.

32. Kosrirukvongs $\mathrm{P}$, Luengchaichawange C. Topical cyclosporine 0.5 per cent and preservative-free ketorolac tromethamine 0.5 per cent in vernal keratoconjunctivitis. J Med Assoc Thai. 2004;87:190-197.

33. Chen J, Dong F, Chen W, et al. Clinical efficacy of $0.1 \%$ pranoprofen in treatment of dry eye patients: a multicenter, randomized, controlled clinical trial. Chin Med J (Engl). 2014;127(13):2407-2412.

34. Baklayan GA, Muñoz M. The ocular distribution of (14)C-labeled bromfenac ophthalmic solution $0.07 \%$ in a rabbit model. Clin Ophthalmol. 2014;8:1717-1724. doi:10.2147/OPTH.S66638

35. Malhotra M, Majumdar DK. Permeation through cornea. Indian J Exp Biol. 2001;39(1):11-24.

36. Lawrence MS, Miller JW. Ocular tissue permeabilities. Int Ophthalmol Clin. 2004;44(3):53-61. doi:10.1097/00004397200404430-00008

37. Bromsite [package insert]. Cranbury, NJ: Sun Pharmaceutical Industries, Inc.; 2016.

38. Si EC, Bowman LM, Hosseini K. Pharmacokinetic comparisons of bromfenac in DuraSite and Xibrom. J Ocul Pharmacol Ther. 2011;27(1):61-66. doi:10.1089/jop.2010.0103

39. Walsh DA, Moran HW, Shamblee DA, et al. Antiinflammatory agents. 3. Synthesis and pharmacological evaluation of 2-amino3-benzoylphenylacetic acid and analogues. J Med Chem. 1984;27 (11):1379-1388. doi:10.1021/jm00377a001

40. Sancilio LF, Nolan JC, Wagner LE, Ward JW. The analgesic and antiinflammatory activity and pharmacologic properties of bromfenac. Arzneimittelforschung. 1987;37(5):513-519.

41. Ruiz J, López M, Milà J, Lozoya E, Lozano JJ, Pouplana R. QSAR and conformational analysis of the antiinflammatory agent amfenac and analogues. J Comput Aided Mol Des. 1993;7(2):183-198. doi:10.1007/BF00126444

42. Kida T, Kozai S, Takahashi H, Isaka M, Tokushige H, Sakamoto T. Pharmacokinetics and efficacy of topically applied nonsteroidal anti-inflammatory drugs in retinochoroidal tissues in rabbits. PLoS One. 2014;9(5):e96481. doi:10.1371/journal.pone.0096481

43. Walters T, Raizman M, Ernest P, Gayton J, Lehmann R. In vivo pharmacokinetics and in vitro pharmacodynamics of nepafenac, amfenac, ketorolac, and bromfenac. J Cataract Refract Surg. 2007;33(9):1539-1545. doi:10.1016/j.jcrs.2007.05.015

44. Waterbury LD, Silliman D, Jolas T. Comparison of cyclooxygenase inhibitory activity and ocular anti-inflammatory effects of ketorolac tromethamine and bromfenac sodium. Curr Med Res Opin. 2006;22 (6):1133-1140. doi:10.1185/030079906X112471
45. Baklayan GA, Patterson HM, Song CK, Gow JA, McNamara TR. 24-hour evaluation of the ocular distribution of (14)C-labeled bromfenac following topical instillation into the eyes of New Zealand white rabbits. J Ocul Pharmacol Ther. 2008;24(4):392398. doi:10.1089/jop.2007.0082

46. Sheppard JD, Cockrum PC, Justice A, Jasek MC. In vivo pharmacokinetics of bromfenac ophthalmic solution $0.075 \%$, Bromfenac ophthalmic solution $0.07 \%$, and nepafenac/amfenac ophthalmic suspension $0.3 \%$ in rabbits. Ophthalmol Ther. 2018;7(1):157-165. doi:10.1007/s40123-018-0130-1

47. Akpek EK, Vittitow J, Verhoeven RS, et al. Ocular surface distribution and pharmacokinetics of a novel ophthalmic 1\% azithromycin formulation. J Ocul Pharmacol Ther. 2009;25(5):433-439. doi:10.1089/jop.2009.0026

48. Hosseini K, Walters T, DaVanzo R, Lindstrom RL. A randomized double-masked study to compare the ocular safety, tolerability, and efficacy of bromfenac $0.075 \%$ compared with vehicle in cataract surgery subjects. Clin Ophthalmol. 2016;10:2311-2317. doi:10.2147/OPTH.S120428

49. Miyake K, Ogawa T, Tajika T, Gow JA, McNamara TR. Ocular pharmacokinetics of a single dose of bromfenac sodium ophthalmic solution $0.1 \%$ in human aqueous humor. J Ocul Pharmacol Ther. 2008;24(6):573-578. doi:10.1089/jop.2007.0132

50. Bucci FA Jr, Waterbury LD. Aqueous prostaglandin E(2) of cataract patients at trough ketorolac and bromfenac levels after 2 days dosing. Adv Ther. 2009;26(6):645-650. doi:10.1007/s12325-0090042-5

51. Bucci FA Jr, Waterbury LD. Prostaglandin E2 inhibition of ketorolac $0.45 \%$, bromfenac $0.09 \%$, and nepafenac $0.1 \%$ in patients undergoing phacoemulsification. Adv Ther. 2011;28:1089-1095. doi:10.1007/s12325-011-0080-7

52. Walters TR, Smyth-Medina RJ, Cockrum PC. An ex vivo human aqueous humor-concentration comparison of two commercial bromfenac formulations. Clin Ophthalmol. 2018;12:943-947. doi:10.2147/OPTH.S170540

53. Russo A, Morescalchi F, Vezzoli S, et al. Reduction of vitreous prostaglandin e2 levels after topical administration of indomethacin $0.5 \%$, bromfenac $0.09 \%$, and nepafenac 0.1. Retina. 2016;36 (6):1127-1131. doi:10.1097/IAE.0000000000000860

54. Heier JS, Awh CC, Busbee BG, et al. Vitreous nonsteroidal antiinflammatory drug concentrations and prostaglandin E2 levels in vitrectomy patients treated with ketorolac $0.4 \%$, bromfenac 0.09\%, and nepafenac 0.1\%. Retina. 2009;29(9):1310-1313. doi:10.1097/IAE.0b013e3181b094e6

55. Jones J, Francis P. Ophthalmic utility of topical bromfenac, a twice-daily nonsteroidal anti-inflammatory agent. Expert Opin Pharmacother. 2009;10(14):2379-2385. doi:10.1517/14656560903092197

56. Hoy SM. Bromfenac ophthalmic solution $0.07 \%$ : a review of its use after cataract surgery. Clin Drug Investig. 2015;35(8):525-529. doi:10.1007/s40261-015-0309-3

57. Rajpal RK, Ross B, Rajpal SD, Hoang K. Bromfenac ophthalmic solution for the treatment of postoperative ocular pain and inflammation: safety, efficacy, and patient adherence. Patient Prefer Adherence. 2014;8:925-931. doi:10.2147/PPA.S46667

58. Sheppard JD. Topical bromfenac for prevention and treatment of cystoid macular edema following cataract surgery: a review. Clin Ophthalmol. 2016;10:2099-2111. doi:10.2147/OPTH.S86971

59. Li SM, Zhan S, Li SY, et al. Laser-assisted subepithelial keratectomy (LASEK) versus photorefractive keratectomy (PRK) for correction of myopia. Cochrane Database Syst Rev. 2016;2: CD009799. doi:10.1002/14651858.CD004158.pub3

60. Kuryan J, Cheema A, Chuck RS. Laser-assisted subepithelial keratectomy (LASEK) versus laser-assisted in-situ keratomileusis (LASIK) for correcting myopia. Cochrane Database Syst Rev. 2017;2:CD011080. 
61. Cleaveland NA, De Mann DW, Carlson NE, Keil ML. Efficacy and perioperative timing of bromfenac in the management of ocular discomfort after femtosecond laser-assisted laser in situ keratomileusis. J Cataract Refract Surg. 2017;43(2):183-188. doi:10.1016/j. jcrs.2016.11.042

62. Chen S, Jiang Y, Yu C, Li Y. Comparison of clinical effects of bromfenac sodium ophthalmic solution $0.1 \%$ versus glucocorticoids for post-LASEK usage. Chin J Ophthalmol. 2015;51(1):4550 .

63. Dong Y, Zhang Y, Xia Y, Wang B, Chen Y. Efficacy observation of $0.1 \%$ bromfenac sodium eye drops on relieving the postLASEK irritative symptoms. Chin $J$ Ophthalmol. 2015;51 (1):51-54.

64. Durrie DS, Kennard MG, Boghossian AJ. Effects of nonsteroidal ophthalmic drops on epithelial healing and pain in patients undergoing bilateral Photorefractive Keratectomy (PRK). Adv Ther. 2007;24(6):1278-1285. doi:10.1007/BF02877774

65. Sher NA, Golben MR, Bond W, Trattler WB, Tauber S, Voirin TG Topical bromfenac $0.09 \%$ vs. ketorolac $0.4 \%$ for the control of pain, photophobia, and discomfort following PRK. $J$ Refract Surg. 2009;25(2):214-220.

66. Wang XJ, Wong SH, Givergis R, Chynn EW. Evaluation of analgesic efficacy of bromfenac sodium ophthalmic solution $0.09 \%$ versus ketorolac tromethamine ophthalmic solution $0.5 \%$ following LASEK or Epi-LASIK. Clin Ophthalmol. 2011;5:1451-1457.

67. Xu Y, Zhao X, Zhang FJ, et al. The clinical efficacy of $0.1 \%$ bromfenac sodium hydrate ophthalmic solution after excimer laser in situ keratomileusis. Chin J Ophthalmol. 2013;49(4):320326.

68. Pinna A, Blasetti F, Ricci GD, Boscia F. Bromfenac eyedrops in the treatment of diabetic macular edema: a pilot study. Eur $J$ Ophthalmol. 2017;27(3):326-330. doi:10.5301/ejo.5000888

69. Radwan AE, Arcinue CA, Yang P, Artornsombudh P, Abu Al-Fadl EM, Foster CS. Bromfenac alone or with single intravitreal injection of bevacizumab or triamcinolone acetonide for treatment of uveitic macular edema. Graefes Arch Clin Exp Ophthalmol. 2013;251(7):1801-1806. doi:10.1007/s00417-013-2309-4

70. Shimura M, Yasuda K. Topical bromfenac reduces the frequency of intravitreal bevacizumab in patients with branch retinal vein occlusion. $B r J$ Ophthalmol. 2015;99(2):215-219. doi:10.1136/bjoph thalmol-2013-304720

71. Grant CA. Combination therapy: lucentis (ranibizumab injection) and Xibrom (bromfenac ophthalmic solution) $0.09 \%$ in the treatment of choroidal neovascular membrane secondary to age-related macular degeneration. Invest Ophthalmol Vis Sci. 2008;49:563. doi:10.1167/iovs.07-0624

72. Flaxel C, Schain MB, Hamon SC, Francis PJ. Prospective randomized controlled trial of combination ranibizumab (Lucentis) and bromfenac (Xibrom) for neovascular age-related macular degeneration: a pilot study. Retina. 2012;32(3):417-423. doi:10.1097/ IAE.0b013e318229b0af

73. Gomi F, Sawa M, Tsujikawa M, Nishida K. Topical bromfenac as an adjunctive treatment with intravitreal ranibizumab for exudative age-related macular degeneration. Retina. 2012;32(9):1804-1810. doi:10.1097/IAE.0b013e31825be87f

74. Wygledowska-Promienska D, Piotrowska-Gwóźdź A, PiotrowskaSeweryn A, Mazur-Piotrowska G, Rokicki W. Combination of bevacizumab and bromfenac therapy in age-related macular degeneration: a pilot study. Med Sci Monit. 2014;20:1168-1175. doi:10.12659/MSM.890197

75. Wygledowska-Promienska D, Piotrowska-Gwóźdź A, PiotrowskaSeweryn A, Mazur-Piotrowska G. Combination of aflibercept and bromfenac therapy in age-related macular degeneration: a pilot study aflibercept and bromfenac in AMD. Med Sci Monit. 2015;21:3906-3912. doi:10.12659/MSM.895977
76. Georgakopoulos CD, Tsapardoni F, Makri OE. Effect of bromfenac on pain related to intravitreal injections: a randomized crossover study. Retina. 2017;37(2):388-395. doi:10.1097/IAE.0000000000 001137

77. Miyake-Kashima M, Takano Y, Tanaka M, et al. Comparison of $0.1 \%$ bromfenac sodium and $0.1 \%$ pemirolast potassium for the treatment of allergic conjunctivitis. Jpn J Ophthalmol. 2004;48 (6):587-590. doi:10.1007/s10384-004-0127-2

78. Fujishima H, Fukagawa K, Takano Y, et al. Comparison of efficacy of bromfenac sodium $0.1 \%$ ophthalmic solution and fluorometholone $0.02 \%$ ophthalmic suspension for the treatment of allergic conjunctivitis. J Ocul Pharmacol Ther. 2009;25(3):265-270. doi:10.1089/jop.2008.0121

79. Uchio E, Itoh Y, Kadonosono K. Topical bromfenac sodium for long-term management of vernal keratoconjunctivitis. Ophthalmologica. 2007;221(3):153-158. doi:10.1159/000099294

80. Fujishima H, Fuseya M, Ogata M, Murat D. Efficacy of bromfenac sodium ophthalmic solution for treatment of dry eye disease. Asis Pac J Ophthalmol (Phila). 2015;4(1):9-13. doi:10.1097/APO. 0000000000000032

81. Usui M, Masuda K. Effect of bromfenac sodium (AHR-10282B) eye drops on anterior uveitis. Jpn Rev Clin Ophthalmol. 1997;91 (5):739-744.

82. Donnenfeld ED, Holland EJ, Durrie DS, Raizman MB. Doublemasked study of the effects of nepafenac $0.1 \%$ and ketorolac $0.4 \%$ on corneal epithelial wound healing and pain after photorefractive keratectomy. Adv Ther. 2007;24(4):852-862. doi:10.1007/ BF02849978

83. Daruich A, Matet A, Moulin A, et al. Mechanisms of macular edema: beyond the surface. Prog Retin Eye Res. 2018;63:20-68. doi:10.1016/j.preteyeres.2017.10.006

84. Pournaras C, Tsacopoulos M, Chapuis P. Studies on the role of prostaglandins in the regulation of retinal blood flow. Exp Eye Res. 1978;26(6):687-697. doi:10.1016/0014-4835(78)90103-3

85. Scholl S, Augustin A, Loewenstein A, Rizzo S, Kupperman B. General pathophysiology of macular edema. Eur J Ophthalmol. 2011;21(Suppl 6):S10-S19. doi:10.5301/EJO.2010.6050

86. Boscia F. Current approaches to the management of diabetic retinopathy and diabetic macular oedema. Drugs. 2010;70(16):21712200. doi:10.2165/11538130-000000000-00000

87. Wolfensberger TJ, Gregor ZJ. Macular edema-rationale for therapy. Dev Ophthalmol. 2010;47:49-58.

88. Zhang R, Liu Z, Zhang H, Zhang Y, Lin D. The COX-2-selective antagonist (NS-398) inhibits choroidal neovascularization and subretinal fibrosis. PLoS One. 2016;11(1):e0146808. doi:10.1371/journal.pone. 0146808

89. Sahoo S, Barua A, Myint KT, Haq A, Abas AB, Nair NS. Topical non-steroidal anti-inflammatory agents for diabetic cystoid macular oedema. Cochrane Database Syst Rev. 2015; (2):CD010009.

90. Flaxman SR, Bourne RRA, Resnikoff S, et al; On behalf of the Vision Loss Expert Group of the Global Burden of Disease Study. Global causes of blindness and distance vision impairment 1990-2020: a systematic review and meta-analysis. Lancet Glob Health. 2017;5(12):e1221-e1234. doi:10.1016/S2214-109X (17)30393-5.

91. American Academy of Ophthalmology Retina/Vitreous Panel. Preferred Practice Pattern ${ }^{\circledR}$ Guidelines. Age-Related Macular Degeneration. San Francisco, CA: American Academy of Ophthalmology; 2015. Available from https://www.aao.org/pre ferred-practice-pattern/age-related-macular-degeneration-ppp2015. Accessed March 26, 2018.

92. Wang Y, Wang VM, Chan CC. The role of anti-inflammatory agents in age-related macular degeneration (AMD) treatment. Eye (Lond). 2011;25(2):127-139. doi:10.1038/eye.2010.196 
93. Segal O, Segal-Trivitz Y, Nemet AY, Cohen P, Geffen N, Mimouni M. Anxiety levels and perceived pain intensity during intravitreal injections. Acta Ophthalmol. 2016;94(2):203-204. doi:10.1111/ aos.2016.94.issue-2

94. Rifkin L, Schaal S. Shortening ocular pain duration following intravitreal injections. Eur J Ophthalmol. 2012;22(6):1008-1012. doi:10.5301/ejo.5000147

95. Ulrich JN. Topical nepafenac after intravitreal injection: a prospective double-masked randomized controlled trial. Retina. 2014;34 (3):509-511. doi:10.1097/IAE.0b013e3182a0e611

96. American Optometric Association. Care of the patient with ocular surface disorders. Optometric Clinical Practice Guideline. St. Louis, MO; 2010

97. American Optometric Association. Care of the patient with anterior uveitis. Optometric Clinical Practice Guideline. St Louis, MO; 2010.

98. Nebbioso M, Del Regno P, Gharbiya M, Sacchetti M, Plateroti R, Lambiase A. Analysis of the pathogenic factors and management of dry eye in ocular surface disorders. Int J Mol Sci. 2017;18(8): E1764. doi:10.3390/ijms 18081764

99. Ballas Z, Blumenthal M, Tinkelman DG, Kriz R, Rupp G. Clinical evaluation of ketorolac tromethamine $0.5 \%$ ophthalmic solution for the treatment of seasonal allergic conjunctivitis. Surv Ophthalmol. 1993;38 Suppl:141-148. doi:10.1016/0039-6257(93)90038-9
100. Yaylali V, Demirlenk I, Tatlipinar S, et al. Comparative study of $0.1 \%$ olopatadine hydrochloride and $0.5 \%$ ketorolac tromethamine in the treatment of seasonal allergic conjunctivitis. Acta Ophthalmol Scand. 2003;81(4):378-382. doi:10.1034/j.16000420.2003.00079.x

101. Laibovitz RA, Koester J, Schaich L, Reaves TA. Safety and efficacy of diclofenac sodium $0.1 \%$ ophthalmic solution in acute seasonal allergic conjunctivitis. J Ocul Pharmacol Ther. 1995;11 (3):361-368. doi:10.1089/jop.1995.11.361

102. Sand BB, Krogh E. Topical indometacin, a prostaglandin inhibitor, in acute anterior uveitis. A controlled clinical trial of non-steroid versus steroid anti-inflammatory treatment. Acta Ophthalmol (Copenh). 1991;69(2):145-148. doi:10.1111/j.1755-3768.1991. tb02703.x

103. Congdon NG, Schein OD, von Kulajta P, Lubomski LH, Gilbert D, Katz J. Corneal complications associated with topical ophthalmic use of nonsteroidal antiinflammatory drugs. $J$ Cataract Refract Surg. 2001;27(4):622-631. doi:10.1016/ S0886-3350(01)00801-X

104. Gaynes BI, Fiscella R. Topical nonsteroidal anti-inflammatory drugs for ophthalmic use: a safety review. Drug Saf. 2002;25 (4):233-250. doi:10.2165/00002018-200225040-00002
Clinical Ophthalmology

\section{Publish your work in this journal}

Clinical Ophthalmology is an international, peer-reviewed journal covering all subspecialties within ophthalmology. Key topics include: Optometry; Visual science; Pharmacology and drug therapy in eye diseases; Basic Sciences; Primary and Secondary eye care; Patient Safety and Quality of Care Improvements. This journal is indexed on PubMed

\section{Dovepress}

Central and CAS, and is the official journal of The Society of Clinical Ophthalmology (SCO). The manuscript management system is completely online and includes a very quick and fair peer-review system, which is all easy to use. Visit http://www.dovepress.com/ testimonials.php to read real quotes from published authors. 